RUNNING HEAD: Error orientation at work

\title{
Error orientation at work: dimensionality and relationships with errors and
} organizational cultural factors.

3

4

Farnese, M. L., Fida, R., \& Picoco, M.

5

6

7

8

$9 \quad$ Paper published in Current Psychology:

10 Farnese, M. L., Fida, R., \& Picoco, M. (2020) Error orientation at work: Dimensionality

11 and relationships with errors and organizational cultural factors. Current Psychology, 1-20.

12 DOI: $10.1007 / \mathrm{s} 12144-020-00639-\mathrm{x}$

13

14 
2 Making errors represents a stressful event, and the way errors are dealt with are significantly

3 influenced by individuals' error orientation. Drawing on the stress literature, scholars have identified

4 several dimensions underpinning error orientation construct. Nevertheless, empirical studies have

5 overlooked the construct complexity and do not provide clear theoretical anchors for its

6 operationalization. This study aims to contribute to the error orientation literature by proposing and

7 empirically testing a theoretical framework that integrates stress and attitude theories, on a sample of

8443 employees. Specifically, we examined the error orientation facets' relationships with both two

9 Hofstede's cultural factors (i.e., power distance and uncertainty avoidance) and work errors (i.e.,

10 slips/lapses and mistakes types). Findings from the test of alternative models and from a structural

11 equation model showed the uniqueness of each facet, also in relation to additional study variables,

12 supporting the relevance of adopting this twofold theoretical framework in order to better understand 13 the nature of each facet.

14

15 Keywords: Error orientation, Power distance culture, Uncertainty avoidance culture, Errors, Hofstede.

16

17 This study was carried out in accordance with the recommendations of the Ethic Committee of the

18 first author's Department. All subjects gave written informed consent in accordance with the

19 Declaration of Helsinki. 
Errors are part of our daily lives. Every individual is occasionally confronted with oversights, omissions, lapses, wrong actions, misunderstandings, misjudgments or mistakes. This assumption is also valid in relation to one's work life. Indeed, "people make mistakes, machines break. No one is perfect and no organization is likely to achieve this ideal" (LaPorte \& Consolini, 1991, p.19). However, although errors are undesirable performance failures that may lead to negative consequences - such as frustration and stress, delay in goal attainment, loss of time and income, or even injuries or accidents - they may also contribute to subsequent performance (Frese \& Keith, 2015). Indeed, they allow for improvements and new insights,

9 for instance by providing valuable feedback to analyze the situation or by increasing

10 motivation to change routines, learn something new or develop innovations (Edmondson \& 11 Lei, 2014; van Dyck, Frese, Baer, \& Sonnentag, 2005). transactional stress theory (Lazarus \& Folkman, 1984), have conceived errors as stressful events to cope with. Indeed, the way individuals appraise wrong actions and their willingness to perceive the potentially positive consequences of errors is influenced by the orientation towards errors. Individuals with a positive orientation perceive errors as learning opportunities, appraise them in a favorable light, and tend to constructively cope with them (Harteis, Bauer, \& Gruber, 2008; Rybowiak et al., 1999). They also use the experience of errors as a motivational basis for engaging in reflective processes with the goal of adopting effective strategies to be resilient to their negative outcomes, prevent further errors, extract their informative value and learn for the future (Frese \& Keith, 2015; Harteis et al., 2008). Vice versa, individuals with a negative orientation perceive errors as threats, appraise them with strain and frustration, and tend to deny or hide them when they occur (Edmondson \& Lei, 2014; Rybowiak et al., 1999; Zhao \& Olivera, 2006). Negative attitudes tend to activate a 
deflating cycle that leads to subsequent errors. This may be due, for instance, to negative emotions (such as anxiety or concern) that distract resources from effective error management (Brown, Westbroo, \& Challagalla, 2005; Hobfoll, 2011). In addition, when individuals attempt to hide a mistake, for example by denying one's own responsibility, this might prevent changes and inhibit learning for future work tasks (Edmondson \& Lei, 2014).

Consistent with this framework, Rybowiak and colleagues (1999) conceptualized error orientation as a construct involving eight facets related to the appraisal and coping processes to manage stressors. However, after reviewing the literature, it is still not clear how the theory is specifically reflected to these dimensions. Moreover, empirical studies that adopted this model have tended to overlook the theoretical framework, merging or selecting some of the eight dimensions without clearly explaining their assumptions. In light of this, the aim the present paper is to contribute to the theoretical conceptualization of error orientation by proposing and empirically testing a twofold frame incorporating stress theory with attitude theory.

Indeed, scholars have highlighted that attitudes may be depicted not only by their positive-negative valence, but also by their components (beliefs, emotions and intentions to behave; Ajzen, 1989; Rosenberg \& Hovland, 1960). Thus, error orientation may be further conceived of as the individual attitude toward errors, expressing a cognitive component (e.g., believing that mistakes are helpful to improve future decisions, trusting that the earlier an error is detected the lesser its consequences will be, or thinking that monitoring one's own

21 behavior is important to promptly detect possible erroneous actions); an affective component (e.g., feeling anxious or guilty or careful in the case of making an error); and a behavioral component (e.g., being willing to recover a wrong action as soon as possible, or trying to 24 cover it up, or relying on teammates' help). 
This tripartite view of attitudes (Rosenberg \& Hovland, 1960) also assumes that each component may express different evaluations, either negative or positive. Thus, error orientation dimensions may describe positive or negative thoughts, positive or negative emotions, and positive or negative behavioral orientations. This may be the case of employees who believe that errors will lead to improvements, but at the same time feel anxious or are willing to cover up their own errors. Taken together, the three components and their valence may support positive or negative reactions. For instance, by analyzing employees' attitude towards change, Piderit (2000) showed that when all components had a positive valence, change was allowed. Conversely, the non-consistency among component valence could foster ambivalence toward change, with potentially debilitating effects on responses to change (i.e., 11 resistance).

In order to better understand the nature of the different error orientation facets, this paper further aims to analyze whether and how each facet 1) may provide a unique contribution to containing or enhancing erroneous behavior; and 2) may be shaped by cultural factors. With respect to our first aim, to the best of our knowledge, although some studies have investigated the relationship of error orientation with errors (Drach-Zahavy \& Pud, 2010; Farnese et al., 2018; Hofmann \& Mark, 2006; Mark et al., 2007), none have considered all of the error orientation dimensions, leaving this important issue unexplored.

As to the second aim, in line with transactional stress theory (Lazarus \& Folkman, 1984) and the subsequent assumption that individuals' orientations toward errors are not generalized responses (Huish \& Poropat, 2008), we will further examine the relationships between error orientation and cultural factors. Indeed, organizational culture expresses the shared beliefs and values through which employees make sense of reality and contributes to determine the way they represent work events, their feelings and their behavioral choices to solve problems. 
1 Regular audit inspections, an error management approach in training, the analysis of customer complaints and keeping near-miss records for accountability are examples of organizational practices that underlie a cultural orientation that conceives errors as a source for learning. At the same time, the adoption of these practices strengthens employees' adherence to consistent norms and values. This study will specifically focus on Hofstede's $(1984,2001)$ cultural dimensions, in line with some scholars' suggestion that they may be particularly relevant for dealing with errors in work contexts (Gelfand, Frese, \& Salmon, 2011).

Overall, this paper aims to contribute to the conceptualization of individual attitudes towards errors, providing stronger theoretical roots to the error orientation dimensionality, a prominent topic in organizational life. This study also aims to provide initial evidence on the specific relationship that each facet can have with errors (enhancing or hindering the likelihood of making them) and with cultural factors (namely, when organizational cultures have a high level of power distance relationships and when they are low tolerant of uncertainty).

\section{Conceptual framework and hypotheses}

Error orientation, a multidimensional construct

Drawing on the transactional stress framework (Lazarus \& Folkman, 1984), Rybowiak and colleagues (1999) stated that the way employees interpret and deal with the occurrence of an error (namely, a stressful event) depends on their error orientation, which is the way they perceive and appraise an error. Consequently, they proposed a multidimensional construct and a related scale (the EOQ-Error Orientation Questionnaire), initially including six facets: error competence, the tendency of developing the knowledge and capability to promptly cope with errors; learning from errors, the tendency of using errors to plan and improve work processes to avoid wrong behavior in the future; error risk taking, a state of openness and flexibility 
1 towards errors; error strain, the general tendency of feeling negative emotions (e.g., fear,

2 embarrassment, and anger) when errors are evoked; error anticipation, a general awareness

3 that errors will happen as well as recurrent negative thoughts about them; and covering up

4 errors, the tendency to deny or hide an error, in order to avoid being blamed. In a later study,

5 the authors (Rybowiak et al., 1999) added two further dimensions: thinking about errors, the

6 tendency of being aware of and carefully reflecting on one's own mistakes; and error

7 communication, the tendency to openly share information about errors with colleagues.

In order to summarize the empirical literature on error orientation adopting Rybowiak and colleagues' model, a qualitative review has been conducted. To find publications for inclusion, we searched WoS databases using specific keywords linked to the Error Orientation

11 Questionnaire and to Rybowiak et al.'s (1999) seminal work. We also used a snowball approach by searching the references of relevant publications to identify further papers. Inclusion criteria were: $a$ ) publications that measured EOQ or some of its scales; $b$ ) temporary 14 lag from 1999 to July 2019; c) selection of empirical papers and dissertations, whereas other scholarly publications (conference papers, working papers, and practitioner publications) were removed. The final list included 34 publications and 36 studies (see Table 1).

The review shows that very few studies have included all eight facets, most of them relying on a few facets or only one. For instance, some authors solely focused on facets related to the problem/emotion-focused behavioral coping strategies, ignoring appraisal facets (Fruhen \& Keith, 2014; Tjosvold, Yu, \& Hui, 2004; van Dyck et al., 2005). Also, risk taking

21 and error anticipation have been used less frequently than other facets and, when used, the latter showed low reliability which resulted in its exclusion from further analyzes. When taking in consideration the structure of the EOQ scale, the literature review also demonstrates 
1 aggregation of some facets. Particularly, some studies aggregated the facets according to their

2 positive versus negative attitude toward errors thus defining two broader dimensions (i.e.

3 error management versus error aversion; van Dyck et al., 2005), or three dimensions by

4 splitting the negative orientation into its strain and covering up components (Bauer \&

5 Mulder, 2013; Leicher \& Mulder, 2016). Moreover, some studies have blurred the model by

6 merging some facets with other constructs. Overall, the literature seems to suggest a

7 fragmented view of the error orientation construct, with alternative models not consistent with

8 Rybowiak et al.'s (1999) and no studies that have explored the factorial structure of the EOQ

9 scale including all (and only) the error orientation facets.

\section{[INSERT-TABLE-1-ABOUT-HERE]}

In the next sections we compare models rooted in different theoretical frameworks. Specifically, according to the literature review depicted above, and in line with both the stress (Lazarus \& Folkman, 1984) and attitude frameworks (Rosenberg \& Hovland, 1960), we hypothesize five alternative models to define the error orientation construct (see Table 2).

\section{Error orientation by adopting the stress framework}

Rooted in Lazarus and Folkman's (1984) stress model, we can trace some of Rybowiak and colleagues' facets to the appraisal of erroneous actions (i.e., one positive facet, risk and two negative, anticipation and strain). We can also connect the other facets to the different coping strategies for dealing with erroneous behaviors: four of them refer to problem-focused strategies (thinking, communication, competence, and learning) and one expresses an emotion-focused coping strategy (covering up). Thus, an error orientation model (M1) based on stress theory as depicted above would be four-faceted, respectively reflecting the positive and negative appraisal of errors, and the problem- and emotion-focused behavioral strategies. 
On the other hand, some authors (Fruhen \& Keith, 2014; Harteis et al., 2008; van Dyck, 2005) considered error strain as a reaction to negative emotions and merged it with covering up in a general avoidant coping strategy. An alternative model to M1 may then be a fourfaceted model (M2) as follow: positive appraisal of errors (risk), negative appraisal of errors (anticipation), problem-focused coping strategies (thinking, communication, competence, learning; the so-called "error management approach") and emotion-focused coping strategies (strain, covering up; the so-called "error aversion approach').

Error orientation by adopting the attitude framework

Error orientation can also be described by drawing on attitude theory (Ajzen, 1989; Rosenberg \& Hovland, 1960), specifically considering attitude's positive and negative valences. In particular, five error orientation facets capture the positive valence toward errors (risk, thinking, communication, competence, learning) whereas the other three capture the negative valence (anticipation, strain, covering up). In line with this, a more parsimonious model (M3) would propose a dichotomic conceptualization of error orientation, one facet expressing a positive attitude toward errors and the other a negative one. This model is consistent with authors that conceive error orientation as bipartite (e.g., Fruhen \& Keith, 2014; Tjosvold et al., 2004; van Dyck et al., 2005), although none of them tested it including all of the eight dimensions.

In addition, drawing on the tripartite attitude model (Rosenberg \& Hovland, 1960), error orientation facets can be also described considering the cognitive, affective and behavioral components. In particular, three error orientation facets capture the beliefs about errors (risk, learning, anticipation), one captures the affective component (strain) and the other four capture the behavioral orientation to cope with errors (thinking, communication, competence, covering up). Thus, by integrating the positive/negative valence of the attitude with the 
1 tripartite model we could suggest a five-facet model (M4) reflecting a positive (risk, learning)

2 and a negative (anticipation) cognitive component, an affective component (strain), and a

3 positive (thinking, communication, competence) and negative (covering up) behavioral

4 component.

$5 \quad$ Error orientation by adopting both the attitude and stress frameworks

6 Given the relevance of both stress and attitude theories we may also integrate them and

7 suggest another model (M5). Specifically, three error orientation facets are related to the

8 appraisal process: one captures a positive belief about errors (risk taking); one a negative

9 belief about errors (anticipation); a third one is related to the affective component (strain).

10 The other five facets are related to the coping process. One expresses a positive cognitive

11 orientation planning how to deal with errors (learning). Three facets express the problem

12 focused coping strategies: one related to redefying the problem (thinking); another one related

13 to seeking for social support (communication); another one to problem solving (competence).

14 The last facet expresses the emotion focused coping strategies related to denial (covering up).

\section{Individual error orientation and errors}

The role that employees' error orientation plays within many work processes is well known. Indeed, it has been extensively studied in relation to several personal work-related variables such as self-esteem, self-efficacy, readiness for change and personal initiative (Rybowiak et al., 1999). In addition, research has shown error orientation's relationship with dispositional variables such as goal orientation (Arenas, Tabernero, \& Briones, 2006; Schell \& Conte, 2008), positive motivational state (Amini \& Mortazavi, 2012) and work-related attitudes (Fay \& Frese, 2000). Some scholars have also examined error orientation in relation to performance (e.g., Arenas et al., 2006), reflection at work (Hetzner, Gartmeier, Heid, \& Gruber, 2011) and meta-cognitive processes (Keith \& Frese, 2005; König et al., 2007; Steele- 
1 Johnson \& Kalinoski, 2014). By applying the individual error orientation at the organizational

2 level (Putz, Schilling, Kluge, \& Stangenberg, 2013; Schell, 2012), others have attested its

3 relationship with organizational performance indicators, such as economic performance and

4 firm goal achievement (van Dyck et al., 2005), team innovativeness (Tjosvold \& Yu, 2007)

5 and leadership (Korsten, Stanz, \& Blignaut, 2004).

6 The relationship between error orientation and positive performance seems to be

7 supported by some empirical evidence. Specifically, employees who have a positive attitude

8 towards errors also activate learning processes that in turn lead to better performance (Keith

9 \& Frese, 2005; Arenas et al., 2006; Steele-Johnson \& Kalinoski, 2014; Dimitrova, van Dyck,

10 van Hooft, \& Groenewegen, 2015). Surprisingly, however, few studies have investigated the

11 relationship between error orientation and performance failure. Exceptions are Mark and

12 colleagues' studies, which found that nurses' positive orientations toward errors (thinking,

13 communication and low covering up, aggregated with other variables) predicted lower

14 medication errors and higher adverse events (Chang \& Mark, 2011; Hofmann \& Mark, 2006).

15 Other scholars have shown that problem-focused coping strategies (the so-called error

16 management approach) decreased healthcare errors (Drach-Zahavy \& Pud, 2010; Farnese et

17 al., 2018). The role of facets expressing a negative orientation have been explored to a lesser

18 extent.

19 To further investigate the role of each error orientation facet, the second aim of this paper

20 is to examine whether and how the different facets are associated with employees' errors at

21 work. Specifically, we propose that each dimension may provide a specific contribution in the

22 attitude-behavior relationship.

23 With respect to the attitudes' framework and their basic bidirectional valence (Rosenberg

24 \& Hovland, 1960) and in line with previous findings, we hypothesized that the error 
1 orientation facets expressing a positive attitude towards errors will be associated with fewer

2 employee errors. Specifically, employees oriented towards the early detection and careful

3 analysis of errors (thinking), to their prompt recovery (competence), to openly sharing

4 information about errors with teammates (communication) and those believing errors may be

5 a source for improving (learning), will also make less errors. Indeed, when employees

6 perceive an erroneous situation as a learning opportunity (Dahlin, Chuang, \& Roulet, 2018)

7 and the learning outcome as controllable (Pekrun, Frenzel, Goetz, \& Perry, 2007), they will

8 infuse more effort in their tasks (Dimitrova et al., 2015) and will be more prone to apply

9 proactive strategies, such as seeking for constructive feedback (Winters \& Latham, 1996).

10 This in turn will lead to a better understanding of work processes and more knowledge about

11 how to successfully perform their job (Stern, Katz-Navon, \& Naveh, 2008). In general, in line

12 with stress theories, we assume that positively oriented employees will perceive errors as less

13 threatening events, thus inducing a lower resource loss (Hobfoll, 2011), and will adopt

14 problem-focused coping strategies, being more effective in managing stress (Brown et al.,

15 2005; King \& Beher, 2017). In addition, by taking an agentic perspective (Bandura, 2018), we

16 can further suppose that these orientations support individual's forethought capability,

17 motivating employees to create action plans, regulate their behavior to achieve the expected

18 standards, and enhance their self-reflectiveness (Chang \& Mark, 2011; Drach-Zahavy \& Pud,

19 2010; Farnese et al., 2018; Hofmann \& Mark, 2006).

20 An exception among the positive facets may be risk taking. Indeed, employees high in

21 risk-taking assume that some errors are inevitable to achieve work results or even that it is

22 better to make mistakes than not accomplish anything (Rybowiak et al., 1999). Their low

23 alertness for possible error occurrence could decrease monitoring behaviors, thus enhancing

24 the frequency of errors (Horvath \& Zuckerman, 1993). In summary, we hypothesize a 
significant and negative relationship between thinking, communication, competence, and learning facets and errors, as well as a positive risk-errors relationship.

On the other hand, following Rybowiak and colleagues (1999) we can suppose that the error orientation facets expressing negative believes (anticipation), affects (strain) and intentions to behave (covering up) will be positively associated with a higher frequency of employee errors. Specifically, employees who think that the likelihood of erring in performing their task is high (anticipation), who feel negative emotions if errors occur (strain), and who aim to hide their erroneous actions (covering up), will also more likely make more errors. Indeed, emotion-focused coping strategies, aimed to modulate unpleasant affect engendered by an error experience, tend to reduce one's responsibility and proactivity in reparative actions and will lead to resignation. Thus, employees will hide the erroneous action and avoid reporting the error (covering up), thereby increasing the likelihood of persisting in making errors (Webb et al., 2012). Further, drawing on the emotion-regulation literature (Webb, Miles \& Sheeran, 2012), we can propose that the tendency to prevent the occurrence of an unpleasant event (anticipation) or to feel negative emotions evoked by errors (strain), are appraisal processes that will interfere with cognitive processes and distract resources away from tasks and when handling errors (Hobfoll, 2011), subsequently enhancing their frequency. Conversely, it is also plausible that individuals who anticipate possible errors and are stressed by committing errors, will make less errors because it makes them more aware and cautious (Brown et al., 2005; Fogarty, 2005; King \& Beeher, 2017; Zhao \&

21 Olivera, 2006).

We further hypothesize that the strength of the attitude-behavior relationship may be different for different facets. Specifically, following the tripartite attitude conceptualization (Ajzen, 1989), we propose that cognitive (risk, learning, anticipation) and affective (strain) 
1 attitudes toward errors will have a looser association with employees' errors, in comparison to

2 behavioral intentions (thinking, communication, competence, covering up).

\section{The role of Hofstede's cultural factors}

Literature on error orientation assumes it is a personal attitude that may be shaped by

6 specific contextual variables, affecting the individuals' appraisal of the straining event and

7 their consequent reactions (Huish \& Poropat, 2008; Lazarus \& Folkman, 1984; Zotzmann,

8 van der Linden, \& Wyrwa, 2019). Indeed, cultural background permeates organizational life

9 by defining the set of shared assumptions and beliefs. These, in turn, provide meaning and

10 models for employees' work attitudes, perceptions and behaviors, including the way they

11 cope with errors. For instance, Hofstede (1990; 2011) defines cultures as collective phenomena that distinguish the members of one group from others. At the organizational level, they are embedded in visible and conscious practices, namely the employees' shared perception of how activities and social interactions unfold in their organization (Hofstede, 2011; Taras, Kirkman, \& Steel, 2010).

Rybowiak and colleagues (1999) have suggested that Hofstede's (1984) cultural factors could influence the way employees deal with errors and learn from them. As well, Gelfand and colleagues (2011) suggested that some cultural variables (e.g., uncertainty avoidance and power distance, among others) might affect employees' attitudes and beliefs about errors, and thereby contribute to the occurrence of errors.

Consequently, the third aim of this study is to further examine the error orientation conceptualization by testing the relationships among its dimensions and cultural factors. We specifically focused on the role played by two prominent cultural factors proposed by 
1 Hofstede $(1984,2001)$-power distance and uncertainty avoidance- which the literature has

2 highlighted as particularly relevant with respect to errors (Gelfand et al., 2001).

Power distance refers to the extent to which people expect and accept an unequal distribution of power between levels in the social system (Hofstede, 1984). Organizations with high power distance tend to rely on hierarchically stratified structures, more centralized decisions and autocratic leadership (Hofstede, 2001). This type of work environment often results in a reduction of the lines of communication between operational personnel and management and affects decision-making processes (e.g., managers do not seek to ensure employees' participation, disagreement cannot be expressed) (Bialas, 2009; Hofstede, 1984; Liu, Yang, \& Nauta, 2013).

To test the error orientation multidimensional model, we will analyze whether the different error orientation facets have specific relationships with cultures supporting power distance. We hypothesize that the communication regarding threatening topics, such as the occurrence of an erroneous action, will be more problematic when these cultures are strong. For instance, employees may feel they receive little to no support when an error happens (Cole, Carter, \& Zhang, 2013) and be reluctant to report errors (Shimizu \& Hitt, 2011). Thus, we propose employees will shun away from communicating with others and evade asking for support in the case of errors (that is, a significant and negative power distancecommunication relationship).

Further, when working in cultural contexts with high levels of power distance, employees tend to avoid seeking feedback about their performance related to errors (König et al., 2007) and to turn a blind eye on their colleagues' or own errors (Zotzmann et al., 2019). They do not engage in extra-role behaviors (such as discussion of faulty work procedures or other interpersonally threatening situations) nor they question their leaders' behaviors and decisions 
1 (Helmreich, Wihelm, Klinect, \& Merritt, 2001; Liu et al., 2013). Thus, we suggest that employees will tend to deny their own responsibility for wrong actions and are more likely to cover them up (that is, a significant and positive power distance-covering up relationship).

In high power-distance organizational cultures, employees also share the belief that errors can be threatening events (e.g., expecting that, when an error occurs, they could be punished

6 for their flaws or losing face or even their jobs), therefore being highly aware of their possible occurrence and feeling feared or shamed when an error happens. Thus, we hypothesize that in these contexts, employees will demonstrate a higher general negative attitude towards errors (that is, a significant and positive power distance-anticipation relationship) and stronger negative emotions related to error occurrence (that is, a significant and positive power 11 distance-strain relationship).

Overall, an erroneous event enhances employees' strain and their tendency to counteract the erroneous action by denying, hiding or underestimating personal responsibility for its occurrence (König et al., 2007). This, in turn, exerts detrimental implications on communicative and decisional processes (Hofstede, 1984) and activates a "vicious cycle" that leads to persisting in errors and hindering learning from them (Catino, 2008; Edmondson \& Lei, 2014). Thus, we further hypothesized that high power-distance cultures shape employees' negative attitudes toward errors, paving the way to more frequent work errors (that is, error orientations will mediate the power distance-errors relationship).

Uncertainty avoidance defines the way the members of an organization feel when in 21 unknown or ambiguous situations (Hofstede, 1984). Employees working in cultures with high levels of uncertainty-avoidance are guided by the desire for predictability and structure in their work and relationships (Hofstede, 2001). They are also more risk aversive in their

24 decision-making (Ladbury \& Hinsz, 2009) and attempt to minimize the anxiety of the 
1 unknown by establishing well-defined policies, formal rules and laws to impose certainty to

2 various domains of life (Gelfand et al., 2011). This leads to increased control by closely

3 monitoring the environment, placing emphasis on error awareness and prevention, adhering to

4 well-structured routines and standard operating procedures (Mohamed, Ali, \& Tam, 2009).

$5 \quad$ Overall, the literature suggests that high levels of uncertainty avoidance may imply a loss

6 of flexibility that might reduce the resilience of the system when something unexpected

7 happens (Gelfand et al., 2011). Thus, the occurrence of an error -which by definition is an

8 unexpected outcome due to an alteration of planned procedure or usual routine- might

9 represent a serious stressor in these cultural contexts. We hypothesize that employees, when

10 working in strongly uncertainty-avoidant cultures, will be oriented towards low risk taking

11 (that is, a significant and negative uncertainty avoidance-risk relationship) and may feel

highly strained when an error occurs (that is, a significant and positive uncertainty avoidance-

13 strain relationship).

On the other hand, cultures high in uncertainty avoidance might support positive coping

strategies aimed at the early detection of errors, effectively recovering and learning from them. Specifically, we hypothesized that employees tend to preserve clear and effective operative standards to monitor their work performance for error refrain, and to quickly detect them once they occur (that is, a significant and positive uncertainty avoidance-thinking relationship). In these cultures, employees also feel free to communicate with colleagues to solve negative consequences (Baker \& Carson, 2011), being more oriented towards asking for help (that is, a significant and positive uncertainty avoidance-communication relationship). They will be also more committed to quickly managing errors to avoid worse consequences (that is, a significant and positive uncertainty avoidance-competence relationship). Further, while in these cultures employees adhere to established norms, rules, procedures and routines, 
they also flexibly adapt or change them to acquire a safer position in the future. Thus, we propose that they are likely to believe errors may have an informative value to avoid future errors (that is, a significant and positive uncertainty avoidance-learning relationship).

Overall, we hypothesize that uncertainty avoidant cultures, shaping employees' positive attitudes toward errors, are associated with lower levels of work errors (that is, error orientations will mediate the uncertainty avoidance-errors relationship).

The hypothesized model is summarized in Figure 1.

\section{Method}

\section{1 \\ Participants and procedures}

Participants included 443 Italian employees. Their mean age was 44.25 years $(\mathrm{SD}=$ 11.58), and $43.6 \%$ were males. About $50.3 \%$ of the sample had a high school degree, while $35.5 \%$ had a university degree or more $(9.5 \%)$. They worked for their current organization for an average of 15.27 years $(\mathrm{SD}=11.41)$ and had a mean job tenure of 19.70 years $(\mathrm{SD}=11.45)$.

With regard to their job position, $11.5 \%$ were managers; $27.9 \%$ white-collar workers; $27.3 \%$ specialized technicians; and $32.3 \%$ blue-collar workers.

Data were collected by students as part of their bachelor's thesis, using a convenience sampling procedure. To ensure variability, each student approached between 10 and 30 employees, which resulted in a sample drawn from very heterogeneous sectors, type and size

21 (Table 3). Participants voluntarily participated in the study and did not receive any kind of reward, financial or otherwise. Each participant received the questionnaire in a blank envelope and a presentation letter, which contained a brief description of the research, its 
main objectives, and a guarantee for the confidentiality of their responses. The ethic committee of the department to which one of the authors is affiliated approved the study.

[INSERT-TABLE-3-ABOUT-HERE]

\section{Measures}

Error orientation was measured by the 37-item Error Orientation Questionnaire (EOQ) by Rybowiak and colleagues (1999). The EOQ measures the following eight facets: error risk taking (4 items); thinking about errors (5 items); error communication (4 items); error competence (4 items); learning from errors (4 items); error anticipation (5 items); error strain (5 items); and covering up errors (6 items). Items are listed in Table 6. Each item asked to what extent it applied to them, on a 5-point Likert scale ranging from $1=$ not at all to $5=$ totally. Items were translated in Italian using the back-translation method. Specifically, in a first step two of the authors independently translated the items. Next, authors discussed the individual solutions. Since no relevant problem emerged, they agreed on the most appropriate version and the final wording. Because the measurement model (CFA) of this scale is one of the research questions that includes also testing alternative models, it is reported in the result section.

Power distance and uncertainty avoidance (Hofstede, 1981) were assessed adopting the scale developed by Dorfman and Howell (1988). In particular, rather than asking how the culture should be (values), following Hofstede's suggestions for tapping organizational cultures, we asked how they actually perceive their organizational culture in practice. Power distance was measured by a 5-item scale assessing the extent to which the members of an organization accept a vertical distribution of power (e.g., "Managers make most decisions without consulting subordinates"). Similarly, uncertainty avoidance was assessed by a 5-item 
1 scale which describes the degree the organization has structured, well-defined and formalized

2 procedures and routines aimed to ensuring the predictability and stability of the work

3 experience (e.g., "We have job requirements and instructions spelled out in detail, so that

4 employees always know what they are expected to do"). Responses were given on a 5-point

5 Likert scale ranging from $1=$ not at all true to 5= completely true. Preliminary CFA supported

6 the dimensionality of the scale $\left(\chi^{2}(33)=113.66, \mathrm{p}<.01 ; \mathrm{CFI}=.95 ; \mathrm{RMSEA}=.074(\mathrm{CI}=.059-\right.$

$7.089), \mathrm{p}<.01 ; \mathrm{SRMR}=.052)$. Loadings ranged from .49 to .85 and the two dimensions correlated

8 with each other (i.e., .15).

Work errors were assessed using a scale generated ad hoc for this study to detect employees' perceptions about the occurrence of some typical errors performed within daily work activities. The scale was designed by using both top-down and bottom-up approaches. Specifically, we drew on Reason's (1990) error classical taxonomy, which distinguishes between wrong actions due to the incorrect execution of a correct action sequence (i.e., slips, operative errors; and lapses, omission errors) and wrong actions due to the correct execution of an incorrect rule or procedure (i.e., mistakes, interpretation errors that result from incomplete or outdated knowledge, or using incorrect information regarding which procedures apply). We operationalized this conceptualization by using 15 in-depth interviews conducted with employees from different sectors, through the critical interview method (Flanagan, 1954). Based on both the interviews and Reason's categorization, a list of 15 items was produced. Afterwards, one of the authors and an external expert independently assigned 21 items to related dimensions and compared their rate of agreement, reducing the list to 7 items through semantic evaluation. The final list included items related to Reason's (1990) basic two

23 dimensions: slips/lapses; and mistakes due to knowledge or rule-based errors. Items are listed 24 in Table 4. Participants were asked to indicate, according to their own individual perceptions, 
1 the frequency they made the listed errors ("During daily work activities, how often do the

2 following happen to you?') rating items on a Likert scale ranging from $1=$ never or almost

3 never to 5=always or almost always. Preliminary CFA conducted by using a cross validation

4 approach supported the dimensionality of the scale. In particular, we randomly split the sample

5 in two halves and conducted the CFA on the two samples independently. Results showed the

6 adequacy of the two-factor model (Sample 1: $\chi^{2}{ }_{(12)}=20.84, \mathrm{p}<.01 ; \mathrm{CFI}=.98 ; \mathrm{RMSEA}=.058$

$7(\mathrm{CI}=.000-.099), \mathrm{p}=.33 ; \mathrm{SRMR}=.031 ;$ Sample $2: \chi^{2}(12)=21.66, \mathrm{p}<.01 ; \mathrm{CFI}=.98 ; \mathrm{RMSEA}=$

$8.059(\mathrm{CI}=.011-.098), \mathrm{p}=.31 ; \mathrm{SRMR}=.030)$, also when compared with an alternative one-

9 factor model (Total sample two-factor model: $\chi^{2}{ }_{(12)}=33.25, \mathrm{p}<.01 ; \mathrm{CFI}=.98 ; \mathrm{RMSEA}=.063$

$10(\mathrm{CI}=.038-.089), \mathrm{p}=.18 ; \mathrm{SRMR}=.025 ;$ Total sample one-factor model: $\chi_{(13)}^{2}=51.06, \mathrm{p}<.01$;

$11 \mathrm{CFI}=.93 ; \mathrm{RMSEA}=.113(\mathrm{CI}=.081-.146), \mathrm{p}<.01 ; \mathrm{SRMR}=.045)$. Loadings from the CFA on

12 the total sample ranged from .56 to .76 and the two dimensions correlated with each other .76.

13 Descriptive statistics and internal consistency for all the scales are reported in Table 7.

\section{Data analysis}

In order to examine the dimensionality of the error orientation questionnaire, we tested and compared the hypothesized models using a confirmatory factor analysis (CFA) approach.

17 Akaike Information Criteria (AIC), Bayesian information criterion (BIC) and the loglikelihood function were used to compare the alternative factorial models. In addition, Chi square, Root Mean Square Error of Approximation (RMSEA), Comparative Fit Index (CFI) and Standardized Root Mean Square Residual (SRMR) were also considered to examine the

21 fit of each model. These fit indices were evaluated considering the following cutoff criteria: CFI 0.90 or greater (Hu \& Bentler, 1999); RMSEA up to 0.06 and a stringent upper limit of .07 (Hu \& Bentler, 1999; Steiger, 2007); SRMR up to 0.08 (Hu \& Bentler, 1999) as indicating a good fit. Internal consistency of the scales was examined considering both Cronbach's alpha 
1 and the factor score determinacy coefficients. Discriminant validity was then examined by

2 testing a full structural equation model (SEM) considering both power distance and

3 uncertainty avoidance as independent variables of the error orientation dimensions, and

4 slips/lapses and mistakes as the dependent variables. Preliminary to the examination of the

5 hypothesized structural model (Figure 1), we tested the adequacy of the measurement model

6 (Bollen, 1989), followed by a comparison with an alternative one-factor model. This allowed

7 a check of the common method bias (Podsakoff, MacKenzie, Lee, \& Podsakoff, 2012). In

8 addition, when testing the SEM, we defined a common latent variable to take into account the

9 fact that all items were measured using only one source of information. Finally, we tested the

10 indirect effects of cultural factors on errors through error orientation by using the indirect

11 effect test implemented in Mplus. For each of the effects, the bootstrapped confidence

12 intervals were computed.

\section{Results}

\section{Dimensionality of the Error Orientation}

15 As shown in Table 5, the model supporting the eight-facet conceptualization by Rybowiak 16 and colleagues (M5), showed the best fit to the data. An inspection of the modification 17 indices revealed that one source of misfit was due to three significant error covariances (STR5 with STR2, CPT1 with CPT3, and TNK5 with TNK6). Hence, we allowed correlating the residuals of the three pairs of items, since they refer to specific content (respectively, items STR5 and STR2 refer to being worried and afraid of doing something wrong; items

21 CPT1 and CPT3 refer to feeling competent to correct a mistake; and items TNK5 and TNK6 refer to thinking thoroughly about an error that occurred). The fit indices of the revised model were good with the exception of the CFI that was lower than $.90\left(\chi^{2}=1418, d f=598\right.$, $\mathrm{p}<.001 ; \mathrm{CFI}=.86 ; \mathrm{RMSEA}=.055(\mathrm{CI}=.052-.059), \mathrm{p}<.05 ; \mathrm{SRMR}=.066)$. Results showed 
that all of the loadings were significant and higher than .30 with the exception of one item of error anticipation (ANT5) that showed a loading of .25 (Table 6).

As shown in Table 7, most of the error orientation dimensions correlated with each other.

Specifically, positive dimensions were positively related (risk, thinking, communication, competence, learning) and the negative ones as well (anticipation, strain, covering up), thus confirming a common underlying valence, in line with the dichotomic model of attitudes. However, results showed an unexpected pattern of correlations between negative and positive dimensions, because only covering up negatively correlated with all of the positive error orientation facets. This negative relationship did not emerge among the other dimensions: anticipation, although expressing a negative attitude toward errors, correlated positively with

11 all of the positive error orientation facets; and strain correlated negatively with competence, but had no significant relationship (risk-taking, communication and learning) or even a positive relationship (thinking) with the positive EOQ dimensions. Thus, the two negative cognitive (anticipation) and emotional (strain) attitudes, although positively related to the negative behavioral intentions toward errors (covering up), also showed a positive association with positive attitudes.

Finally, Cronbach's alpha analysis supported good internal consistency for all facets, although only sufficient for error anticipation (Table 6).

\section{Discriminant validity}

The measurement model resulted in a good fit: $\chi_{(1307)}^{2}=2,529.7, p<.01 ; C F I=.87$; 
1 factor model showed a poor fit to the data: $\chi_{(1373)}^{2}=7,122.2, p<.001, C F I=.37, R M S E A=.097$

$2(90 \%$ C.I. $=.095-.099), p=.001 ;$ SRMR $=.125$. This suggests the absence of common method

3 bias, supported also by the significant chi-square difference test between the two models ( $p<$

4 .001). However, in order to take into account the possible common method bias, the model

5 was estimated by including the common latent factor. The model fits the data well with the

6 exception of the CFI that was lower than $.90\left(\chi^{2}(1323)=2571.291 ; p<.001 ; \mathrm{CFI}=.86\right.$; RMSEA $=$

$7.046(\mathrm{CI}=.043-.049), \mathrm{p}=.99 ; \mathrm{SRMR}=.062)$. Results of this model (Figure 2) showed that

8 power distance, as hypothesized, was significantly related to the negative facets of error

9 orientation. Specifically, the more the organizational culture lacked participation and had an

10 unequal distribution of power, the more employees felt strained when they made errors

11 (strain: .24, $\mathrm{p}<.001$ ), and tended to hide or deny them (covering up: .21, $\mathrm{p}<.001$ ). They also

12 tended to not communicate with teammates about errors nor seek help and support from them

13 (communication: $-.27,<.001$ ). The model also showed the hypothesized relationships

14 between uncertainty-avoidant cultures and EOQ facets. Indeed, the more employees valued

15 their organizational culture oriented towards enhancing predictability and reducing ambiguity,

16 the more employees carefully analyzed mistakes that occurred (thinking: .37, $\mathrm{p}<.001$ ),

17 promptly corrected them (competence: .33, $\mathrm{p}<.001$ ), told others about them and relied on

18 colleagues for help (communication: .27, $\mathrm{p}<.001$ ) and used negative feedback to improve in

19 the future (learning: .18, $\mathrm{p}<.001$ ). They also felt more strained when an error occurred

20 (strain: .10, $\mathrm{p}<.05)$. Risk-taking resulted unrelated $(.08, \mathrm{p}=.278)$.

21 Furthermore, results showed that two positive dimensions, competence and communications, were related to error reduction (specifically, competence-mistakes: -.26; $\mathrm{p}<.001 ;$ competence-slips/lapses: -.76; $\mathrm{p}<.001$; communication -mistakes: -.16; $\mathrm{p}<.05$ ).

24 Conversely, the positive risk-taking dimension was positively related to errors (risk- 
1 slips/lapses: .27; $\mathrm{p}<.001)$. Anyhow the positive thinking-slips/lapses relationship should not

2 be interpreted; indeed, given the nonsignificant correlation between these two variables and

3 the high correlation of thinking with the other EOQ facets, it is possible that the significant

4 beta coefficient is a statistical artefact of the regression. Conversely, the two anticipation and

5 covering up negative dimensions were positively related to errors (anticipation-mistakes: .39;

$6 \quad \mathrm{p}<.001 ;$ covering up-slips/lapses: .19; $\mathrm{p}<.001)$, whereas strain was not. The model also

7 showed that power distance was directly associated with both slips and mistakes

8 (respectively, .22 $\mathrm{p}<.000$, and $.14 \mathrm{p}<.05$ ). Results of the indirect effects showed that power

9 distance is associated with slips through covering $(\beta=0.038, \mathrm{p}<.05)$ and uncertainty

10 avoidance is associated with both slips and mistakes through competence (respectively, $\beta=-$

$11.25 \mathrm{p}<.01 ; \beta=-.086 \mathrm{p}<.01)$. Overall, the model explained $37 \%$ of the variance of slips and $12 \quad 25 \%$ of mistakes.

[INSERT-FIGURE-2-ABOUT-HERE]

\section{Discussion}

This paper aimed to contribute to the error orientation conceptualization by providing theoretical anchors to its multidimensionality. The test of alternative models showed that the model incorporating the stress theory with the attitude theory had a better fit than the more parsimonious ones. This model overcomes the positive-negative dichotomy often adopted by scholars, supporting the complex eight-facet error orientation proposed by Rybowiak and colleagues (1999). Specifically, results from the measurement model showed that all eight dimensions contributed to the construct definition, the weaker ones included. Indeed, the error competence dimension proved to have adequate internal reliability, similar to that of the Dutch version by Rybowiak and colleagues, but in contrast to the lower reliability found in 
1 their English version (Rybowiak et al., 1999) and in other studies (Schell \& Conte, 2008).

2 Also error anticipation, a dimension seldom used in the literature or deleted because of poor

3 reliability, demonstrated sufficient psychometric properties in the present study.

This finding is also supported by correlations among error orientation dimensions, that showed some unexpected patterns, suggesting that merging all of the negative dimensions in a

6 single approach would lose informative value. Indeed, the anticipation and strain from error

7 appraisal dimensions, although expressing negative attitudes toward errors, were not related

8 to the positive error orientation facets. This is in line with some empirical evidence suggesting

9 that strain and covering up could tap separate processes that do not conceptually coincide

10 neither lead to the same outcomes (see van Dyck et al., 2005). We propose that strain could

11 have a nonlinear relationship with the positive facets, since this emotional dimension,

12 although eliciting negative feelings, may contribute not only to emotion-focused strategies,

13 but also to problem-focused strategies. Future research should verify a possible interactive

14 contribution of strain to the adoption of different coping strategies, or explore boundary conditions that turn strain toward problem-focused rather than emotion-focused coping strategies. For instance, the psychological safety climate among teammates could moderate the strain-learning relationship (Edmondson \& Lei, 2014).

Overall, the model based on the twofold frame is consistent with the stress theory, acknowledging the specificity of the appraisal and coping processes. It is also in line with the tripartite view of attitudes, which holds that the cognitive, affective and behavioral orientations represent conceptually distinct components that, although related to the same underlying attitude, express different categories of psychological significance and are not completely redundant (Ajzen, 1989).

The present results also allow a better understanding of the role of error orientation facets 
1 in relation to possible cultural factors and error outcomes. In general, they provide some initial

2 evidence consistent with the well-established relationship between positive coping orientations

3 towards errors (communication, competence) and error reduction. Conversely, employees who

4 tend to positively appraise errors, assuming that making errors is an inevitable risk to achieve

5 work results, showed a positive relationship with errors. This facet expresses openness and

6 flexibility towards errors and may imply an underestimation of danger from wrong actions and

7 lower monitoring of one's own behaviors, thus paving the way to errors (Horvath \& Zuckerman, 8 1993).

These results further add to the literature providing empirical support to the overlooked negative orientation-errors relationship. Specifically, employees who tend to adopt a negative

11 appraisal about errors by expressing pessimistic expectations (anticipation) and those who tend to adopt covering up emotion-focused strategies and fear being blamed when committing an error (covering up), make more errors.

It is worth noting that, although all of these relationships are consistent with our hypotheses, some relationships were not significant. Indeed, cognitive and emotional facets were not related to errors. This seems to be in line with the attitude conceptualization by Ajzen (1989), according to which the behavior component of attitudes is directly related to actual responses (namely, error reduction/increase), whereas cognitive and affective attitudes may be considered distal antecedents. Future longitudinal studies should test a model based on the causal-chain perspective suggested by Ajzen (1989), verifying whether beliefs and affect lead to the intention

21 to behave which, in turn, determine actual behavior (i.e. errors).

The need for a complex conceptualization of error orientation is further supported by our hypotheses, employees working in high uncertainty-avoidance cultures were more oriented 
1 to cope with errors. Thus, the desire for predictability typical of these cultural models enhances

2 employees' tendency to adopt problem-focused strategies in order to avoid larger negative

3 consequences and their repetition in the long run (secondary prevention), although enacting

4 employees' negative affect (strain) toward undesirable events. This result also adds to the

5 uncertainty avoidance literature, supporting conceptualizations of this cultural feature regarding

6 its possible adaptive function, rather than being strictly oriented to predictability (Baker \&

7 Carson, 2011; Schneider \& De Meyer, 1991). The hypothesized uncertainty avoidance-risk

8 negative relationship was not supported.

Similarly, power distance cultures were significantly and positively related to employees’ negative attitudes toward errors. This means that employees holding a perception of

11 imbalanced power relationships among teammates are more likely to experience a negative emotional appraisal, feel shamed or worried about being blamed (error strain) and tend to deny or hide their responsibility for errors (covering up). They also tend to avoid communicating 14 about their own errors and refraining from asking teammates for help (Gelfand et al., 2011; Liu et al., 2013). The hypothesized power distance-anticipation positive relationship was not supported. Results also showed a direct relationship between power distance and errors.

The model, on the whole, partially supported the hypothesized relationships between cultural factors and error orientation. Indeed, most dimensions were related to the two cultural factors, except uncertainty avoidance-risk and power distance-anticipation relationships.

20 Some scholars asserted that error orientation is a malleable personal construct that can be 21 shaped by social contexts (Gelfand et al., 2011; Huish \& Poropat, 2008). Findings of our study highlight that coping dimensions seem to be influenced by cultural context, whereas appraisal

23 dimensions are not. We may suppose that the risk and anticipation non-significant

24 relationships could be due to their general focus (respectively, believing that it is better to err 
1 rather do nothing, and expecting that something will go wrong when working) rather than a

2 focus on a specific work-error experience. In other words, results suggest that organizational

3 culture do not influence the generalized orientations through which individuals interpret and

4 evaluate how threatful errors may be, whereas it seems to change individual level of error

5 orientations when they are related to coping intentions. Nonetheless, future studies are needed

6 to provide stronger empirical support for these preliminary findings, for instance through a

7 multilevel or longitudinal design, that would allow to test causality relationships.

Overall, the composite patterns of relationships between the two cultural factors and the

9 error orientation dimensions underline the usefulness of considering a multidimensional

10 structure for this construct and suggest that merging EOQ's different facets in an overall

11 positive/negative dimension could be misleading, above all when analyzing their relationship

12 with other variables.

13 Finally, the model tested a mediating effect of cultural factors on errors through error

14 orientation, showing a total indirect effect for both uncertainty avoidance and power distance.

15 Thus, cultural norms, practices and shared believes about errors are variously related to

16 different attitudes toward errors, that in turn relate to erroneous behaviors. Future research

17 should explore whether these different relationships could outline specific patterns that, from

18 cultural factors, contribute to enhance/reduce the probability that employees make errors at

19 work, by shaping their error orientation. For instance, following Ajzen and Fishbein's (1980)

20 theory of reasoned action, we could propose that individual attitudes toward errors represent

21 the underlying motivation to perform an action, and that social norms (i.e., believes and

22 perceptions shared in relevant groups, such as organizational or professional contexts) also

23 contribute to how employees will actually engage in a behavior, both directly exerting a 
1 pressure to correctly/erroneously behave, and indirectly affecting it through their behavioral

2 intention attitude.

This study also makes a cross-cultural contribution to the EOQ's validation given that, as

4 far as we know, it is the first study conducted in a Latin European country. Indeed, the

5 national culture in our study differs from the Germanic or Anglo countries where most studies

6 on errors have been conducted, being Italy a country where a blame-guilt culture is widespread,

7 power distance with authorities are stronger, leadership style is less participative and tolerance

8 for ambiguity and uncertainty is lower (Catino, 2008; House, Hanges, Javidan, Dorfman, \&

9 Gupta, 2004; Lorenzoni \& Lewis, 2004). In this way, we embraced Hofstede's (1984) suggestion

10 to enhance cross-cultural research on his dimensions. Anyhow we focused on one single culture,

11 thus further studies considering additional countries (Zotzmann et al., 2019) or specific organizational or professional cultures are needed to check whether errors could be conceived of

13 as more troublesome than in other cultural contexts.

\section{Practical implications}

As errors represent an unavoidable part of an individual's work experience, their role in fostering organizational learning is widely recognized (Frese \& Keith, 2015; Edmondson \& Lei, 2014). Results of this study highlight the importance of cultural factors in shaping employees' attitude toward errors, affecting their awareness and the propensity to learn from them or not. From a practical point of view, this suggests that management should encourage a low power distance culture, where mistakes are not blamed or penalized, while also encouraging employees' awareness about feedback (even when negative) regarding their work or promoting communication about mistakes (König et al., 2007), also exerting a modelling role on how to deal with errors (Farnese et al., 2018). As well, a cultural context oriented to minimize the anxiety of ambiguous situations does not seem to lead to a loss of flexibility when an 
unexpected event happens, rather it seems to enhance the resilience of the system by activating effective coping strategies (Baker \& Carson., 2001). Thus, a work environment designed to establish well-defined policies and formal rules could help not only in preventing errors, but also in reducing their negative consequences after a wrong action and in increasing the likelihood of learning from them, making the organization able to adopt a twofold error handling approach (Frese \& Keith, 2015; Catino, 2008).

The present findings may also be of relevant use in training projects (Amini \& Mortazavi, 2012; Frese \& Keith, 2015; Keith \& Frese, 2005). Raising awareness about preferred personal attitudes, and recognizing their advantages and disadvantages, may help instructors develop interventions that enable trainees to gain confidence in their error-coping competence and to perform more effectively, thereby benefiting both the individual and the organization.

\section{Limitations and directions for future research}

Some limitations of the present study need to be addressed. Firstly, the data were obtained through a self-report questionnaire, raising concerns regarding the eventual common method variance issues. Although the hypotheses were tested while controlling for the common latent factor, the findings of this study must be interpreted cautiously given the limitations of the self-report nature of our data, due for instance to the risk of underestimation of self-assessed work errors or to an overestimation of own error competence or learning capability. Further, the cross-sectional study design precludes the ability to make statements of cause and effect, thus additional research would benefit from longitudinal designs to test the process we hypothesized or alternative ones. For instance, we assumed that individual error orientation leads employees to make less/more errors, but it is also plausible that the frequency of errors that an employee makes can influence their attitude toward them (e.g., 
1 mistakes can occur or, in the opposite case, to perceive themselves as capable in detecting or

2 correcting errors promptly). Similarly, drawing on Lazarus and Folkman's (1984)

3 transactional stress theory, we hypothesized that individuals' orientations toward errors are

4 context-sensitive attitudes, thus their level may change also on the basis of the organizational

5 culture employees are embedded in. However, we could also argue that bottom-up emergent

6 processes might contribute to shape some cultural features (e.g., similar professional

7 backgrounds can lead to shared believes about risk-taking or the value of learning from

8 errors). In addition, to better understand the error orientation sensitivity to contextual factors,

9 future research could also explore the interplay among factors at different levels, for instance

10 adopting a multicenter design or integrating the proposed model with other individual (e.g.,

11 work self-efficacy), interpersonal (e.g., trustworthiness in peers or supervisor, team psychological safety climate), or organizational variables (e.g., safety climate).

Another limitation of this study is related to the representativeness of the sample, as the

14 data were obtained from a convenience sample, and not collected at the organizational level.

15 As such, case studies or multilevel studies could add to the literature. Moreover, having based

16 this study only on one single culture, a comparing approach with employees from other cultures

17 is encouraged for future research (e.g., cross-national studies). Believing that error orientation is

18 a highly culturally sensitive construct, future cross-cultural research needs to be conducted.

\section{References}

21 Ajzen, I. (1989). Attitude structure and behavior. Attitude structure and function, 241-274. Prentice-Hall. 
RUNNING HEAD: Error orientation at work

1 Amini A., \& Mortazavi S. (2012). Effectiveness of psychological capital on mistake management culture as a resource for learning in organisation. International Journal of Human Sciences, 9(2), 339-353.

Arenas, A., Tabernero, C., \& Briones, E. (2006). Effects of goal orientation, error orientation and self-efficacy on performance in an uncertain situation. Social Behavior and Personality, 34(5), 569-586. doi:10.2224/sbp.2006.34.5.569

Baglin J., \& Da Costa C. (2012). An experimental study evaluating error management training for learning to operate a statistical package in an introductory statistics course: Is less guidance more? International Journal of Innovation in Science and Mathematics Education, 20(3), 48-67.

Bandura, A. (2018). Toward a psychology of human agency: Pathways and reflections. Perspectives on Psychological Science, 13(2), 130-136.

Baker, D.S., \& Carson, K.D. (2011). The two faces of uncertainty avoidance: Attachment and

Bauer, J., \& Mulder, R.H. (2013) Engagement in learning after errors at work: Enabling conditions and types of engagement. Journal of Education and Work, 26(1), 99-119. doi:10.1080/13639080.2011.573776

Białas, S. (2009). Power distance as a determinant of relations between managers and employees in the enterprises with foreign capital. Journal of Intercultural Management, $1(2), 105-115$.

Bollen, K.A. (1989). Structural equations with latent variables. New York: Wiley.

Brown, S.P., Westbrook, R.A., \& Challagalla, G. (2005). Good cope, bad cope: Adaptive and maladaptive coping strategies following a critical negative work event. Journal of Applied Psychology, 90(4), 792-798. 
RUNNING HEAD: Error orientation at work

1 Carter, M., \& Beier, M. (2010). The effectiveness of error management training with working-aged adults. Personnel Psychology, 63, 641-675. doi:10.1111/j.17446570.2010.01183.x

Casey, T., \& Krauss, A. (2013). The role of effective error management practices in increasing miners' safety performance. Safety Science, 60, 131-141. doi:10.1016/j.ssci.2013.07.001

Catino, M. (2008). A review of literature: Individual blame vs. organisational function logics in accident analysis. Journal of Contingencies and Crisis Management, 16(1), 53-62. doi:10.1111/j.1468-5973.2008.00533.x

Chang, Y., \& Mark, B. (2011). Moderating effects of learning climate on the impact of RN staffing on medication errors. Nursing Research, 60(1), 32-39.

Chugtai, A.A., \& Buckley, F. (2010). Assessing the effects of organisational identification on in-role job performance and learning behavior. The mediating role of learning goal orientation. Personnel Review, 39(2), 242-258. doi:10.1108/00483481011017444

Dahlin, K.B., Chuang, Y.T., \& Roulet, T.J. (2018). Opportunity, motivation, and ability to learn from failures and errors: Review, synthesis, and ways to move forward. Academy of 
RUNNING HEAD: Error orientation at work

1 Dimitrova, N.G., van Dyck, C., van Hooft, E., \& Groenewegen, P. (2015). Don't fuss, focus: The mediating effect of on-task thoughts on the relationship between error approach instructions and task performance. Applied Psychology, an International Review, 64(3), 599-624.

Dorfman, P.W. \& Howell, J.P. (1988). Dimensions of national culture and effective leadership patterns: Hofstede Revisited. Advances in International Comparative Management, 3(1), 127-150.

Drach-Zahavy, A., \& Pud, D. (2010). Learning mechanisms to limit medication administration errors. Journal of Advanced Nursing, 66(4), 794-805. doi:10.1111/j.13652648.2010.05294.x

Edmondson, A.C., \& Lei, Z. (2014). Psychological safety: The history, renaissance, and future of an interpersonal construct. Annual Review of Organisational Psychology and Organisational Behavior, 1, 23-43. doi:10.1146/annurev-orgpsych-031413-091305

Farnese, M.L., Zaghini, F., Caruso, R., Fida, R., Romagnoli, M., Sili, A. (2018). Managing care errors in the wards: The contribution of authentic leadership and error management culture. Leadership \& Organisation Development Journal, 40(1), 17-30. doi:10.1108/LODJ-04-2018-0152

Fay, D., \& Frese, M. (2000). Conservatives approach to work: Less prepared for future work demands? Journal of Applied Social Psychology, 30, 171-195. doi:10.1111/j.15591816.2000.tb02310.x

Flanagan, J.C. (1954). The critical incident technique. Psychological Bulletin, 51(4), 327358. doi:10.1037/h0061470

Fogarty, G.J. (2005). Psychological strain mediates the impact of safety climate on maintenance errors. International Journal of Applied Aviation Studies, 5(1), 53-64 
RUNNING HEAD: Error orientation at work

1 Frese, M., \& Keith, N. (2015). Action errors, error management, and learning in organisations. Annual Review of Psychology, 66, 661-687. doi:10.1146/annurev-psych010814-015205

Fruhen, L.S., \& Keith, N. (2014). Team cohesion and error culture in risky work environments. Safety Science, 65, 20-27. doi:10.1016/j.ssci.2013.12.011

Gelfand, M.J., Frese, M., \& Salmon, E. (2011). Cultural influences on errors: prevention, detection, and management. Errors in organisations, 273-315.

Harteis, C., Bauer, J., \& Gruber, H. (2008). The culture of learning from mistakes: How employees handle mistakes in everyday work. International Journal of Educational Research, 47, 223-231. doi:10.1016/j.ijer.2008.07.003

Helmreich, R.L., Wilhelm, J.A., Klinect, J.R., \& Merritt, A.C. (2001). Culture, error and crew resource management. Applying resource management in organisations, 305-331.

Hetzner, S., Gartmeier, M., Heid, H., \& Gruber, H. (2011). Error orientation and reflection at work. Vocations and Learning, 4, 25-39. doi:10.1007/s12186-010-9047-0

Hobfoll, S.E. (2011). Conservation of resources theory: Its implication for stress, health, and resilience. The Oxford handbook of stress, health, and coping, 127-147.

Hofmann, D.A., \& Mark, B. (2006). An investigation of the relationships between safety climate and medication errors as well as other nurse and patient outcomes. Personnel Psychology, 59, 847-869. doi:10.1111/j.1744-6570.2006.00056.x

Hofstede, G. (1984). Culture's consequences: International differences in work-related values. Sage.

Hofstede, G. (2001). Culture's consequences: Comparing values, behaviors, institutions and organisations across nations. Sage. doi:10.1177/031289620202700105 
RUNNING HEAD: Error orientation at work

1 Hofstede, G. (2011). Dimensionalizing cultures: The Hofstede model in context. Online Readings in Psychology and Culture, 2(1), 8. doi:10.9707/2307-0919.1014

Horvath, P., \& Zuckerman, M. (1993). Sensation seeking, risk appraisal, and risky behavior. Personality and Individual Differences, 14(1), 41-52. doi:10.1016/0191-8869(93)90173Z

House, R., Hanges, P., Javidan, M., Dorfman, P., \& Gupta, V. (Eds) (2004). Culture, leadership and organisations. The GLOBE study of 62 societies. Sage.

Hu, L., \& Bentler, P.M. (1999). Cutoff criteria for fit indexes in covariance structure analysis: Conventional criteria versus new alternatives. Structural Equational Modeling, 6, 1-55. doi:10.1080/10705519909540118

Huish, K.A., \& Poropat, P. (2008). Coping with error in the workplace. Personality down under: Perspectives from Australia, 125-132.

Keith, N., \& Frese, M. (2005). Self-regulation in error management training: Emotion control and metacognition as mediators of performance effects. Journal of Applied Psychology, 90(4), 677-691. doi:10.1037/0021-9010.90.4.677

King, B.S., \& Beehr, T.A. (2017). Working with the stress of errors: Error management strategies as coping. International Journal of Stress Management, 24(1), 18-33.

König, C., Steinmetz, H., Frese, M., Rauch, A., \& Wang, Z.M. (2007). Scenario-based scales measuring cultural orientations of business owners. Journal of Evolutionary Economics, 17(2), 211-239. doi:10.1007/s00191-006-0047-z

Korsten, V.A., Stanz, K., \& Blignaut, J. (2004). The development of a management error orientation questionnaire. Journal of Human Resource Management, 2, 37-44.

Ladbury, J.L., \& Hinsz, V.B. (2009). Uncertainty avoidance influences choices for potential gains but not losses. Current Psychology, 28, 187-193. doi:10.1007/s12144-009-9056-z 
RUNNING HEAD: Error orientation at work

1 LaPorte, T.R., \& Consolini, P.M. (1991). Working in practice but not in theory: theoretical challenges of "high-reliability organisations". Journal of Public Administration Research and Theory, 1(1), 19-48.

Lauzier, M., \& Mercier, G. (2018). The effect of error orientation, motivation to learn, and social support on training transfer intentions: A moderated mediation model. Canadian Journal of Administrative Sciences/Revue Canadienne des Sciences de l'Administration, 35(3), 419-428.

Lazarus, R.S., \& Folkman, S. (1984). Stress, appraisal, and coping. Springer.

Leicher, V., Mulder, R., \& Bauer, J. (2013). Learning from errors at work: A replication study in elder care nursing. Vocations and Learning, 6, 207-220. doi:10.1007/s12186-0129090-0

Leicher. V., \& Mulder. R. (2016). Individual and contextual factors influencing engagement

Liu, C., Yang, L.Q., Nauta, M.M. (2013). Examining the mediating effect of supervisor conflict on procedural injustice-job strain relations: The function of power distance. Journal of Occupational Health Psychology, 18, 64-74. doi:10.1037/a0030889

Lorenzoni, N., \& Lewis, B.R. (2004). Service recovery in the airline industry: A crosscultural comparison of the attitudes and behaviours of British and Italian front-line personnel. Managing Service Quality: An International Journal, 14(1), 11-25.

Mark, B.A., Hughes, L.C., Belyea, M., Chang, Y., Hofmann, D., Jones, C.A., \& Bacon C. (2007). Does safety climate moderate the influence of staffing adequacy and work conditions on nurse injuries? Journal of Safety Research, 38, 431-446. 10.1016/j.jsr.2007.04.004 
RUNNING HEAD: Error orientation at work

1 Mohamed, S., Ali, T.H., \& Tam, W. (2009). National culture and safe work behavior of construction workers in Pakistan. Safety Science, 47(1), 29-35. doi:10.1016/j.ssci.2008.01.003

Pekrun, R., Frenzel, A.C., Goetz, T., \& Perry, R.P. (2007). The control-value theory of achievement emotions: An integrative approach to emotions in education. In Emotion in education (pp. 13-36). Academic Press.

Piderit S.K. (2000). Rethinking resistance and recognizing ambivalence: A multidimensional view of attitudes toward an organisational change. Academy of Management Review, 4, 783-794. doi:10.5465/amr.2000.3707722

Podsakoff, P.M., MacKenzie, S.B., \& Podsakoff, N.P. (2012). Sources of method bias in social science research and recommendations on how to control it. Annual Review of

Putz, D., Schilling, J., Kluge, A., \& Stangenberg, C. (2013). Measuring organisational learning from errors: development and validation of an integrated model and questionnaire. Management Learning, 44(5), 511-536. doi:10.1177/1350507612444391

Rausch, A., Seifried, J. \& Harteis, C. (2017). Emotions, coping and learning in error situations in the workplace. Journal of Workplace Learning, 29(5), 374-393. doi:10.1108/JWL-01-2017-0004

Reason, J. (1990). Human error. Cambridge University Press.

Rosenberg, M.J., \& Hovland, C.I. (1960). Cognitive, affective, and behavioral components of attitude. Attitude organisation and change, 1-14. (EOQ): Reliability, validity, and different language equivalence. Journal of 
RUNNING HEAD: Error orientation at work

Organisational Behavior, 20, 527-547. doi:10.1002/(SICI)10991379(199907)20:4<527::AID-JOB886>3.0.CO;2-G

Schell, K.L. (2012). The Error-Oriented Motivation Scale: An examination of structural and convergent validity. Personality and Individual Differences, 52(3), 352-356. doi:10.1016/j.paid.2011.10.035

Schell, K.L., \& Conte, J.M. (2008). Associations among polychronicity, goal orientation, and error orientation. Personality and Individual Differences, 44(1), 288-298. doi:10.1016/j.paid.2007.08.009

Schneider, S.C., \& DeMeyer, A. (1991). Interpreting and responding to strategic issues: The impact of national culture. Strategic Management Journal, 12(4), 307-320. doi:10.1002/smj.4250120406

Shimizu, K., \& Hitt, M.A. (2011). Errors at the top of the hierarchy. Errors in Organisations, $199-224$.

Steele-Johnson, D., \& Kalinoski, Z. (2014). Error framing effects on performance: Cognitive, motivational, and affective pathways. Journal of Psychology, 148(1), 93-111. doi:10.1080/00223980.2012.748581

Steiger, J.H. (2007). Understanding the limitations of global fit assessment in structural equation modeling. Personality and Individual Differences, 42(5), 893-898.

Stern, Z., Katz-Navon, T., \& Naveh, E. (2008). The influence of situational learning orientation, autonomy, and voice on error making: The case of resident physicians. Management Science, 54(9), 1553-1564. https://doi.org/10.1287/ mnsc.1080.0862

Taras, V., Kirkman, B.L., \& Steel, P. (2010). Examining the impact of culture's consequences: A three-decade, multilevel, meta-analytic review of Hofstede's cultural 
RUNNING HEAD: Error orientation at work

value dimensions. Journal of Applied Psychology, 95(3), 405-439. doi:10.1037/a0018938

Tjosvold, D., \& Yu, Z. (2007). Group risk taking. The constructive role of controversy in China. Group and Organisation Management, 32, 653-674. doi:10.1177/1059601106287110

Tjosvold, D., Yu, Z., \& Hui, C. (2004). Team learning from mistakes: The contribution of cooperative goals and problem-solving. Journal of Management Studies, 41(7), 12231245. doi:10.1111/j.1467-6486.2004.00473.x

Tulis, M. (2013). Error management behavior in classrooms: Teachers' responses to student mistakes. Teaching and Teacher Education, 33, 56-68. doi:10.1016/j.tate.2013.02.003

Van Dyck, C., Frese, M., Baer, M., \& Sonnentag, S. (2005). Organisational error management culture and its impact on performance: A two-study replication. Journal of Applied Psychology, 90, 1228-1240. doi:10.1037/0021-9010.90.6.1228

Winters, D., \& Latham, G.P. (1996). The effect of learning versus outcome goals on a simple versus a complex task. Group \& Organization Management, 21(2), 236-250.

Webb, T.L., Miles, E., \& Sheeran, P. (2012). Dealing with feeling: A meta-analysis of the effectiveness of strategies derived from the process model of emotion regulation. Psychological Bulletin, 138(4), 775-808. doi:10.1037/a0027600

Yan, Q., Bligh, M., \& Kohles, J. (2014). Absence makes the errors go longer. How leaders inhibit learning from errors. Zeitschriftfür Psychologie, 222(4), 233-245. doi:10.1027/2151-2604/a000190

Zhao, B., \& Olivera, F. (2006). Error reporting in organisations. Academy of Management Review, 31(4), 1012-1030. doi:10.5465/amr.2006.22528167

Zotzmann, Y., van der Linden, D., \& Wyrwa, K. (2019). The relation between country 
RUNNING HEAD: Error orientation at work

1 differences, cultural values, personality dimensions, and error orientation: An approach

2 across three continents-Asia, Europe, and North America. Safety Science, 120, 185-193.

3 doi.org/10.1016/j.ssci.2019.06.013

4

5

6 Acknowledgements: We thank the anonymous reviewers for their careful reading of our

7 manuscript and their many insightful comments and suggestions.

8 
Figure 1. The hypothesized model and direction of relationships.

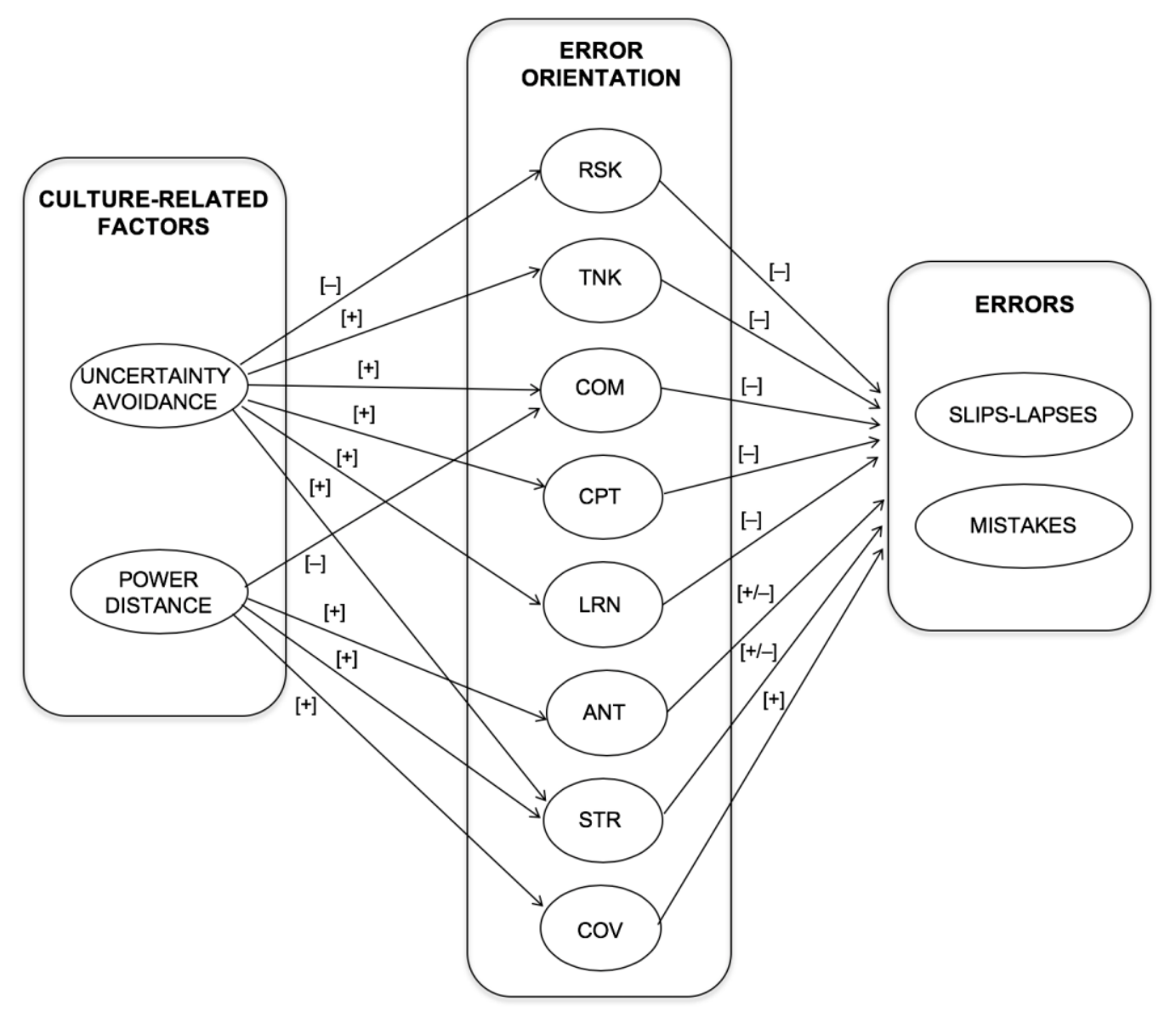

Note: $\mathrm{RSK}=$ error risk taking, $\mathrm{TNK}=$ thinking about errors, $\mathrm{COM}=$ error communication, $\mathrm{CPT}=$ error competence, $\mathrm{LRN}=$ learning from errors, $\mathrm{ANT}=$ error anticipation, $\mathrm{STR}=$ error strain, $\mathrm{COV}=$ covering up errors. 
Figure 2. The tested model.

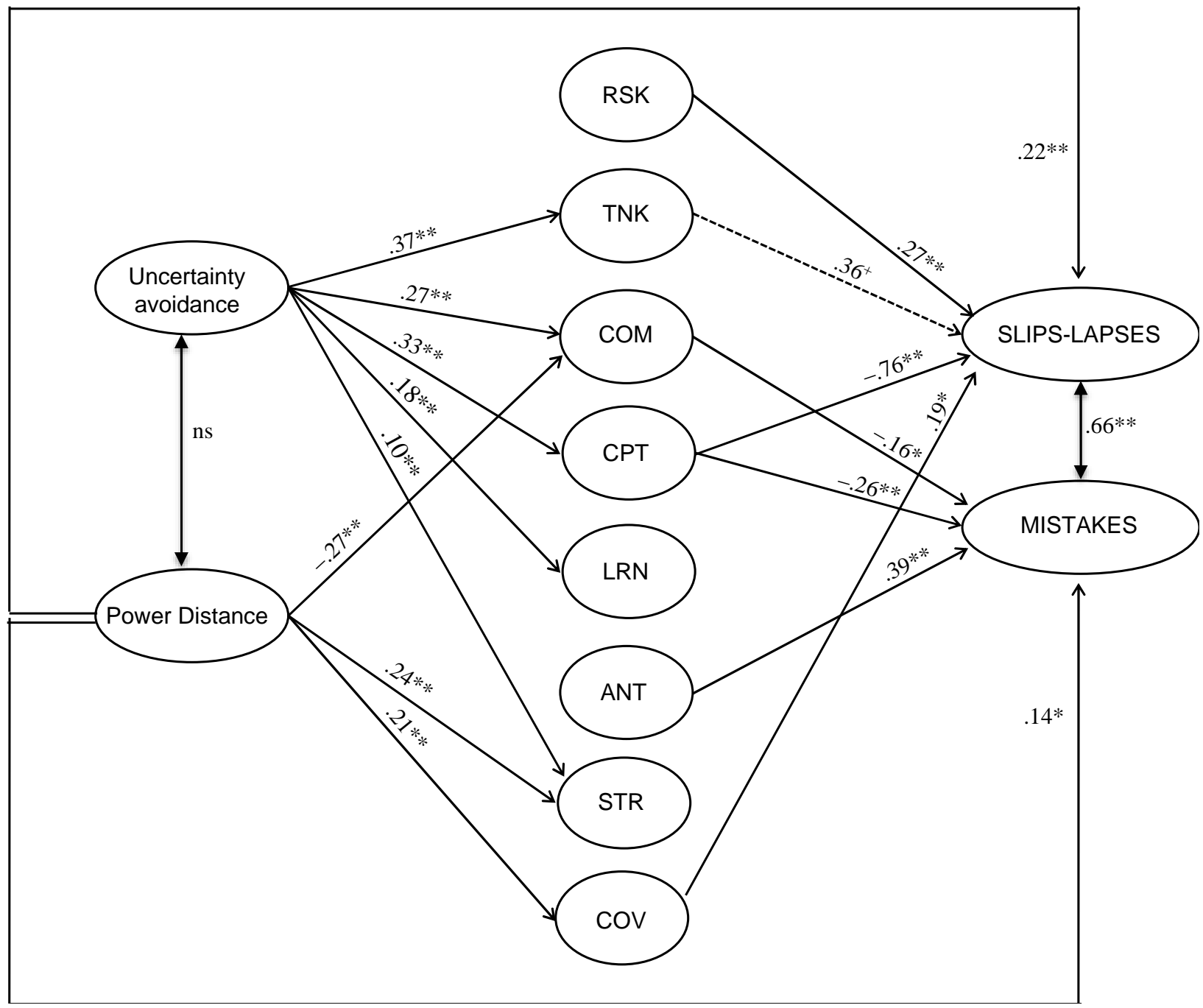

Note: $\mathrm{RSK}=$ error risk taking, $\mathrm{TNK}=$ thinking about errors, $\mathrm{COM}=$ error communication, $\mathrm{CPT}=$ error competence, $\mathrm{LRN}=$ learning from errors, $\mathrm{ANT}=$ error anticipation, $\mathrm{STR}=$ error strain, $\mathrm{COV}=$ covering up errors.

Please note that all the dimensions are latent measured by their indicators. In addition, the model includes the common latent factor that has been estimated but not reported in the figure. 
Table 1. Summary of the studies using the EOQ's scales or variants (in chronological order).

\begin{tabular}{|c|c|c|c|c|c|c|c|c|c|c|c|c|c|}
\hline \multirow[t]{2}{*}{ Source } & \multicolumn{8}{|c|}{ Theoretical dimensions } & \multirow[b]{2}{*}{$\begin{array}{c}N \\
\operatorname{dim}\end{array}$} & \multirow{2}{*}{\multicolumn{3}{|c|}{ Empirical factors }} & \multirow[b]{2}{*}{$\begin{array}{r}N \\
f a c\end{array}$} \\
\hline & $\begin{array}{c}1 \\
R S K\end{array}$ & $\stackrel{2}{T N K}$ & $\stackrel{3}{C O M}$ & $\begin{array}{c}4 \\
C P T\end{array}$ & $\begin{array}{c}5 \\
L R N\end{array}$ & $\begin{array}{c}6 \\
A N T\end{array}$ & $\begin{array}{c}7 \\
\text { STR }\end{array}$ & $\stackrel{8}{\mathrm{COV}}$ & & & & & \\
\hline $\begin{array}{l}\text { Rybowiak et al., } 1999 \\
\text { (Study 1) }\end{array}$ & $\mathrm{X}$ & & & $\mathrm{X}$ & $\mathrm{X}$ & $\mathrm{X}$ & $\mathrm{X}$ & $\mathrm{X}$ & 6 & $\mathrm{X}$ & $\mathrm{X}$ & $\begin{array}{l}\text { 1= RSK; } 4=\mathrm{CMP} ; 5=\mathrm{LRN} ; 6=\mathrm{ANT} ; 7= \\
\text { STR; } 8=\mathrm{COV}\end{array}$ & 6 \\
\hline $\begin{array}{l}\text { Rybowiak et al., } 1999 \\
\text { (Study 2) }\end{array}$ & $\mathrm{X}$ & $\mathrm{X}$ & $\mathrm{X}$ & $\mathrm{X}$ & $\mathrm{X}$ & $\mathrm{X}$ & $\mathrm{X}$ & $\mathrm{X}$ & 8 & -- & $\mathrm{X}^{*}$ & $\begin{array}{l}1=\mathrm{RSK} ; 2=\mathrm{TNK} ; 3=\mathrm{COM} ; 4=\mathrm{CMP} ; 5= \\
\text { LRN; } 6=\mathrm{ANT} ; 7=\mathrm{STR} ; 8=\mathrm{COV}\end{array}$ & 8 \\
\hline Fay \& Frese, 2000 & $\mathrm{X}$ & & & & & & & & 1 & -- & $\mathrm{X}^{* * *}$ & $1=\mathrm{RSK}$ & 1 \\
\hline Korsten et al., 2004 & $\mathrm{X}$ & $\mathrm{X}$ & $\mathrm{X}$ & $\mathrm{X}$ & $\mathrm{X}$ & $\mathrm{X}$ & $\mathrm{X}$ & $\mathrm{X}$ & 8 & $\mathrm{X}^{* * *}$ & -- & $\begin{array}{l}7=\text { stress caused by error; } 2,3,4,8=\text { attitude } \\
\text { of dealing with errors; } 1=\text { RSK ( } 5 \text { and } 6 \\
\text { deleted) }\end{array}$ & 3 \\
\hline Tjosvold et al., 2004 & & $\mathrm{X}$ & $\mathrm{X}$ & & $\mathrm{X}$ & & $\mathrm{X}$ & $\mathrm{X}$ & 5 & -- & $\mathrm{X}^{* * *}$ & $\begin{array}{l}2,3=\text { problem solving approach; } 5=\mathrm{LRN} ; 7 \text {, } \\
8=\text { blaming approach }\end{array}$ & 3 \\
\hline Keith \& Frese, 2005 & & & & & $\mathrm{X}$ & & $\mathrm{X}$ & & 2 & -- & -- & $5=\mathrm{LRN} ; 7=\mathrm{STR}$ & 2 \\
\hline $\begin{array}{l}\text { van Dyck et al., } 2005 \text { (Study } \\
\text { 1) }\end{array}$ & & $\mathrm{X}$ & $\mathrm{X}$ & $\mathrm{X}$ & $\mathrm{X}$ & & $\mathrm{X}$ & $\mathrm{X}$ & 6 & $\mathrm{X}$ & -- & $\begin{array}{l}2,3,4,5=\text { error management; } 7,8=\text { error } \\
\text { aversion }\end{array}$ & 2 \\
\hline $\begin{array}{l}\text { van Dyck et al., } 2005 \text { (Study } \\
\text { 2) }\end{array}$ & & $\mathrm{X}$ & $\mathrm{X}$ & $\mathrm{X}$ & $\mathrm{X}$ & & & & 4 & -- & -- & $2,3,4,5=$ error management & 1 \\
\hline Arenas et al., 2006 & $\mathrm{X}$ & & $\mathrm{X}$ & & & & $\mathrm{X}$ & & 3 & -- & -- & $1=\mathrm{RSK} ; 3=\mathrm{COM} ; 7=\mathrm{STR}$ & 3 \\
\hline Hofmann \& Mark, 2006 & & $\mathrm{X}$ & $\mathrm{X}$ & & & & & $\mathrm{X}$ & 3 & $\mathrm{X}$ & $\mathrm{X}^{* * *}$ & $\begin{array}{l}2,3,8(\text { rev }) \text { +other dimensions= safety } \\
\text { climate }\end{array}$ & 1 \\
\hline König et al., 2007 & & & $\mathrm{X}$ & & & & & & 1 & -- & -- & $3=\mathrm{COM}$ & 1 \\
\hline Mark et al., 2007 & & $\mathrm{X}$ & $\mathrm{X}$ & & & & & $\mathrm{X}$ & 3 & -- & -- & $\begin{array}{l}2,3,8(\mathrm{rev})+\text { other dimensions = safety } \\
\text { climate }\end{array}$ & 1 \\
\hline Tjosvold \& Yu, 2007 & $\mathrm{X}$ & & & $\mathrm{X}$ & & & & & 2 & -- & -- & $1=\mathrm{RSK} ; 4=\mathrm{CPT}$ & 2 \\
\hline Harteis et al., 2008 & $\mathrm{X}$ & $\mathrm{X}$ & $\mathrm{X}$ & $\mathrm{X}$ & $\mathrm{X}$ & $\mathrm{X}$ & $\mathrm{X}$ & $\mathrm{X}$ & 8 & $\mathrm{X}$ & -- & $\begin{array}{l}1,5=\text { appraisal of mistakes; } 2,3=\text { strategies } \\
\text { to learn from mistakes; } 7,8=\text { negative } \\
\text { emotions regarding mistakes ( } 4 \text { and } 6 \\
\text { deleted) }\end{array}$ & 3 \\
\hline Schell \& Conte, 2008 & & & & $\mathrm{X}$ & & & $\mathrm{X}$ & & 2 & -- & -- & $4=\mathrm{LRN} ; 7=\mathrm{STR}$ & 2 \\
\hline Carter \& Beier, 2010 & & & & & $\mathrm{X}$ & & & & 1 & -- & -- & 5= LRN & 1 \\
\hline Cigularov et al., 2010 & & $\mathrm{X}$ & $\mathrm{X}$ & $\mathrm{X}$ & $\mathrm{X}$ & & & & 4 & $\mathrm{X}$ & $\mathrm{X}^{* * * *}$ & $2,3,4,5=$ error management & 1 \\
\hline Chughtai \& Buckley, 2010 & & & $\mathrm{X}$ & & & & & & 1 & -- & -- & $3=\mathrm{COM}$ & 1 \\
\hline Chang \& Mark, 2011 & & $\mathrm{X}$ & $\mathrm{X}$ & & & & & $\mathrm{X}$ & 3 & $\mathrm{X}$ & -- & $2=\mathrm{TNK}, 3=\mathrm{COM} ; 8(\mathrm{rev})=\mathrm{COV}$ & 3 \\
\hline Hetzner et al., 2011 & $\mathrm{X}$ & & & $\mathrm{X}$ & $\mathrm{X}$ & & $\mathrm{X}$ & & 4 & -- & -- & $1=\mathrm{RSK} ; 4=\mathrm{CPT} ; 5=\mathrm{LRN} ; 7=\mathrm{STR}$ & 4 \\
\hline Amini \& Mortzavi, 2012 & $\mathrm{X}$ & $\mathrm{X}$ & $\mathrm{X}$ & $\mathrm{X}$ & $\mathrm{X}$ & $\mathrm{X}$ & $\mathrm{X}$ & $\mathrm{X}$ & 8 & -- & $\mathrm{X}^{* * *}$ & $\begin{array}{l}1=\mathrm{RSK} ; 2=\mathrm{TNK} ; 3=\mathrm{COM} ; 4=\mathrm{CMP} ; 5= \\
\text { LRN; } 6=\mathrm{ANT} ; 7=\mathrm{STR} ; 8=\mathrm{COV}\end{array}$ & 8 \\
\hline
\end{tabular}




\begin{tabular}{|c|c|c|c|c|c|c|c|c|c|c|c|c|c|}
\hline Baglin \& Da Costa, 2012 & & & & & $\mathrm{X}$ & & $\mathrm{X}$ & & 2 & $\mathrm{X}$ & -- & 5= LRN; 7= STR & 2 \\
\hline Bauer \& Mulder, 2013 & & & & & $\mathrm{X}$ & & $\mathrm{X}$ & $\mathrm{X}$ & 3 & -- & $\mathrm{X}^{* * *}$ & 5= LRN; $7=$ STR; $8=\mathrm{COV}$ & 3 \\
\hline Casey \& Krauss, 2013 & & $\mathrm{X}$ & $\mathrm{X}$ & $\mathrm{X}$ & $\mathrm{X}$ & & & & 4 & $\mathrm{X}$ & $\mathrm{X}^{* * * *}$ & $2,3,4,5=$ error management & 1 \\
\hline Leicher et al., 2013 & & & & & $\mathrm{X}$ & & $\mathrm{X}$ & $\mathrm{X}$ & 3 & -- & $\mathrm{X}^{* * * *}$ & 5= LRN; 7= STR; 8= COV & 3 \\
\hline Putz et al., 2013 & & $\mathrm{X}$ & & & $\mathrm{X}$ & & $\mathrm{X}$ & & 3 & -- & -- & $2=\mathrm{TNK} ; 5=\mathrm{LRN} ; 7=\mathrm{STR}$ & 3 \\
\hline Tulis, 2013 & & & $\mathrm{X}$ & & & & & $\mathrm{X}$ & 2 & - & -- & $3=\mathrm{COM} ; 8=\mathrm{COV}$ & 2 \\
\hline Fruhen \& Keith, 2014 & & $\mathrm{X}$ & $\mathrm{X}$ & $\mathrm{X}$ & $\mathrm{X}$ & & $\mathrm{X}$ & $\mathrm{X}$ & 6 & -- & -- & $\begin{array}{l}2,3,4,5=\text { error management; } 7,8=\text { error } \\
\text { aversion }\end{array}$ & 2 \\
\hline $\begin{array}{l}\text { Steele-Johnson \& Kalinoski, } \\
2014\end{array}$ & & & & & $\mathrm{X}$ & & & & 1 & -- & $\mathrm{X}^{* * *}$ & $5=\mathrm{LRN}$ & 1 \\
\hline Yan et al., 2014 & $\mathrm{X}$ & $\mathrm{X}$ & $\mathrm{X}$ & & $\mathrm{X}$ & & $\mathrm{X}$ & $\mathrm{X}$ & 6 & -- & -- & $1,2,3,5,7(\mathrm{rev}), 8(\mathrm{rev})=$ error learning & 1 \\
\hline Leicher \& Mulder, 2016 & & & & & $\mathrm{X}$ & & $\mathrm{X}$ & $\mathrm{X}$ & 3 & -- & $\mathrm{X}^{* * *}$ & 5= LRN; 7= STR; 8= COV & 3 \\
\hline King \& Beher, 2017 & $\mathrm{X}$ & $\mathrm{X}$ & $\mathrm{X}$ & $\mathrm{X}$ & $\mathrm{X}$ & $\mathrm{X}$ & $\mathrm{X}$ & $\mathrm{X}$ & 8 & -- & -- & $\begin{array}{l}1,2,3,4,5=\text { positive error management; } 6, \\
8=\text { negative error management; } 7=\text { strain }\end{array}$ & 3 \\
\hline $\begin{array}{l}\text { Rausch, Seifried \& Harteis, } \\
2017\end{array}$ & $\mathrm{X}$ & $\mathrm{X}$ & $\mathrm{X}$ & $\mathrm{X}$ & $\mathrm{X}$ & $\mathrm{X}$ & $\mathrm{X}$ & $\mathrm{X}$ & 8 & -- & -- & $\begin{array}{l}\text { 1= RSK; } 2=\text { TNK; } 3=\text { COM; } 4=\text { CMP; } 5= \\
\text { LRN; 6= ANT; } 7=\text { STR; } 8=\text { COV }\end{array}$ & 8 \\
\hline Farnese et al., 2018 & & $\mathrm{X}$ & $\mathrm{X}$ & $\mathrm{X}$ & $\mathrm{X}$ & & & & 4 & -- & $\mathrm{X}^{* * * *}$ & $2,3,4,5=$ error management & 1 \\
\hline Lauzier \& Mercier, 2018 & & & & & $\mathrm{X}$ & & $\mathrm{X}$ & & & -- & -- & 5= LRN; 7= STR & 2 \\
\hline Zotzmann et al., 2019 & $\mathrm{X}$ & $\mathrm{X}$ & $\mathrm{X}$ & $\mathrm{X}$ & $\mathrm{X}$ & $\mathrm{X}$ & $\mathrm{X}$ & $\mathrm{X}$ & 8 & -- & -- & $\begin{array}{l}1=\mathrm{RSK} ; 2=\mathrm{TNK} ; 3=\mathrm{COM} ; 4=\mathrm{CMP} ; 5= \\
\text { LRN; } 6=\mathrm{ANT} ; 7=\mathrm{STR} ; 8=\mathrm{COV} \\
\text { and: } 1,2,3,4,5,6,7,8=\text { error orientation }\end{array}$ & $8-1$ \\
\hline $\begin{array}{r}\text { Frequency of } \\
\text { each dimension's use }\end{array}$ & 13 & 19 & 22 & 17 & 26 & 9 & 22 & 19 & & & & & \\
\hline
\end{tabular}

2 * CFA conducted at item level separately on each dimension; ** CFA conducted at facet level; *** Factor analysis conducted including error orientation items and other scales.

Note: $\mathrm{RSK}=$ error risk taking, $\mathrm{TNK}=$ thinking about errors, $\mathrm{COM}=$ error communication, $\mathrm{CPT}=$ error competence, $\mathrm{LRN}=$ learning from errors, $\mathrm{ANT}=$ error anticipation, STR= error strain, $\mathrm{COV}=$ covering up errors. 
Table 2. Summary of the tested models.

\begin{tabular}{|c|c|c|c|c|c|c|c|c|c|}
\hline & $\begin{array}{l}\text { Number } \\
\text { of } \\
\text { factors }\end{array}$ & RSK & TNK & $\mathrm{COM}$ & CPT & $\mathbf{L R N}$ & ANT & STR & $\mathrm{COV}$ \\
\hline \multicolumn{10}{|c|}{ Stress model framework } \\
\hline \multirow[t]{2}{*}{$M 1$} & $\# 4$ & $\mathrm{~F} 1$ & F3 & F3 & F3 & F3 & $\mathrm{F} 2$ & $\mathrm{~F} 2$ & $\mathrm{~F} 4$ \\
\hline & & $\begin{array}{l}\text { Positive } \\
\text { appraisal }\end{array}$ & \multicolumn{4}{|c|}{$\begin{array}{c}\text { Problem-focused } \\
\text { strategy }\end{array}$} & \multicolumn{2}{|c|}{$\begin{array}{l}\text { Negative } \\
\text { appraisal }\end{array}$} & $\begin{array}{c}\text { Emotion- } \\
\text { focused } \\
\text { strategy }\end{array}$ \\
\hline \multirow[t]{2}{*}{$M 2$} & $\# 4$ & $\mathrm{~F} 1$ & F3 & \multirow{2}{*}{\multicolumn{2}{|c|}{$\begin{array}{l}\text { F3 F3 } \\
\begin{array}{c}\text { Problem-focused } \\
\text { strategy }\end{array} \\
\end{array}$}} & F3 & \multirow{2}{*}{$\begin{array}{c}\mathrm{F} 2 \\
\text { Negative } \\
\text { appraisal }\end{array}$} & \multirow{2}{*}{\multicolumn{2}{|c|}{$\begin{array}{l}\text { F4 F4 } \\
\text { Emotion-focused } \\
\text { strategy }\end{array}$}} \\
\hline & & $\begin{array}{c}\text { Positive } \\
\text { appraisal }\end{array}$ & & & & & & & \\
\hline \multicolumn{10}{|c|}{ Attitude theory framework } \\
\hline \multirow[t]{2}{*}{ M3 } & \#2 & $\mathrm{F} 1$ & F1 & F1 & $\mathrm{F} 1$ & $\mathrm{~F} 1$ & $\mathrm{~F} 2$ & $\mathrm{~F} 2$ & $\mathrm{~F} 2$ \\
\hline & & \multicolumn{5}{|c|}{ Positive valence } & \multicolumn{3}{|c|}{ Negative valence } \\
\hline \multirow[t]{2}{*}{ M4 } & $\# 5$ & $\mathrm{~F} 1$ & $\mathrm{~F} 4$ & $\mathrm{~F} 4$ & $\mathrm{~F} 4$ & $\mathrm{~F} 1$ & $\mathrm{~F} 2$ & F3 & F5 \\
\hline & & $\begin{array}{c}\text { Positive } \\
\text { cognitive } \\
\text { component }\end{array}$ & \multicolumn{3}{|c|}{$\begin{array}{l}\text { Positive } \\
\text { behavioral component }\end{array}$} & $\begin{array}{l}\text { Positive } \\
\text { cognitive } \\
\text { component } \\
\end{array}$ & $\begin{array}{l}\text { Negative } \\
\text { cognitive } \\
\text { component }\end{array}$ & $\begin{array}{l}\text { Negative } \\
\text { affective } \\
\text { component }\end{array}$ & $\begin{array}{c}\text { Negative } \\
\text { behavioral } \\
\text { component }\end{array}$ \\
\hline \multicolumn{10}{|c|}{ Rybowiak et al. 's model } \\
\hline \multirow[t]{2}{*}{ M5 } & $\# 8$ & $\mathrm{~F} 1$ & $\mathrm{~F} 2$ & F3 & $\mathrm{F} 4$ & F5 & F6 & F7 & $\mathrm{F} 8$ \\
\hline & & $\begin{array}{l}\text { Positive } \\
\text { appraisal } \\
\text { (belief) }\end{array}$ & $\begin{array}{l}\text { Problem- } \\
\text { focused } \\
\text { coping } \\
\text { (problem } \\
\text { set) }\end{array}$ & $\begin{array}{l}\text { Problem- } \\
\text { focused } \\
\text { coping } \\
\text { (social } \\
\text { support) }\end{array}$ & $\begin{array}{l}\text { Problem- } \\
\text { focused } \\
\text { coping } \\
\text { (problem } \\
\text { solving) }\end{array}$ & $\begin{array}{l}\text { Problem- } \\
\text { focused } \\
\text { coping } \\
\text { (planning) }\end{array}$ & $\begin{array}{l}\text { Negative } \\
\text { appraisal } \\
\text { (belief) }\end{array}$ & $\begin{array}{l}\text { Negative } \\
\text { appraisal } \\
\text { (affective) }\end{array}$ & $\begin{array}{l}\text { Emotion- } \\
\text { focused } \\
\text { coping } \\
\text { (deny) }\end{array}$ \\
\hline
\end{tabular}

Legend: $\mathrm{RSK}=$ error risk taking, $\mathrm{TNK}=$ thinking about errors, $\mathrm{COM}=$ error communication, $\mathrm{CPT}=$ error competence, $\mathrm{LRN}=$ learning from errors, $\mathrm{ANT}=$ error anticipation, $\mathrm{STR}=$ error strain, $\mathrm{COV}=$ covering up errors. 
Table 3. Characteristics of the organizational contexts of the sample.

\begin{tabular}{|c|c|c|}
\hline PRODUCTIVE SECTORS & n. & $\%$ \\
\hline Culture (education, tourism, information) & 54 & 12.2 \\
\hline Trade (food, other goods) & 54 & 12.2 \\
\hline Health and social assistance & 91 & 20.5 \\
\hline Construction and transportation & 64 & 14.4 \\
\hline Services (financial and insurance, consultants) & 62 & 14.0 \\
\hline Security and Army & 11 & 2.5 \\
\hline Public administration and other public services & 98 & 22.1 \\
\hline Others (call centers, cleaning companies) & 9 & 2.0 \\
\hline \multicolumn{3}{|l|}{ TYPE } \\
\hline Private sector & 245 & 55.2 \\
\hline Public sector & 183 & 41.4 \\
\hline Non-for-profit sector & 15 & 3.4 \\
\hline \multicolumn{3}{|l|}{ SIZE } \\
\hline Micro (<15 employees) & 77 & 17.3 \\
\hline Small (16-50 employees) & 51 & 11.5 \\
\hline Medium (51-500 employees) & 118 & 26.6 \\
\hline Large (>500 employees) & 197 & 44.6 \\
\hline \multicolumn{3}{|l|}{ GEOGRAPHICAL LOCATION } \\
\hline Company nationally based, one office & 147 & 33.1 \\
\hline Company nationally based, with local branches & 227 & 51.1 \\
\hline International corporate & 60 & 13.5 \\
\hline Missing & 9 & 2.3 \\
\hline Tot. & 443 & $\begin{array}{c}100 \\
\%\end{array}$ \\
\hline
\end{tabular}

Table 4. Work errors scale (items and descriptive statistics).

\begin{tabular}{|c|c|c|c|c|c|c|}
\hline Item & Mean & $S D$ & Skewness & Kurtosis & $\begin{array}{l}\text { SLIPS/LAPSES } \\
\text { Loadings* }\end{array}$ & $\begin{array}{l}\text { MISTAKES } \\
\text { Loadings } *\end{array}$ \\
\hline 1. Forget to perform a task & 2.22 & 0.82 & .176 & -.557 & .557 & \\
\hline 2. Delay in the performance of a task & 2.49 & 0.85 & .062 & -.489 & .763 & \\
\hline 3. Being distracted when working & 2.82 & 0.88 & -.331 & -.120 & .760 & \\
\hline $\begin{array}{l}\text { 4. Refer to incomplete or outdated } \\
\text { knowledge to perform a task }\end{array}$ & 2.29 & 1.00 & .445 & -.393 & & 662 \\
\hline 5. Use an improper procedure & 2.28 & 0.92 & .466 & -.069 & & .752 \\
\hline $\begin{array}{l}\text { 6. Make decisions not effective for } \\
\text { our customers }\end{array}$ & 2.17 & 0.92 & .374 & -.448 & & .754 \\
\hline $\begin{array}{l}\text { 7. Fail to fully comply with protocols, } \\
\text { procedures, or guidelines }\end{array}$ & 2.00 & 0.97 & .756 & -.052 & & .717 \\
\hline
\end{tabular}


3 Table 5. Results of the hypothesized factors models.

\begin{tabular}{|c|c|c|c|c|c|c|c|c|c|c|c|c|c|}
\hline & \multicolumn{2}{|c|}{ Loglikelihood } & \multirow[t]{2}{*}{$\begin{array}{c}\text { Akaike } \\
\text { (AIC) }\end{array}$} & \multirow[t]{2}{*}{$\begin{array}{c}\text { Bayesian } \\
\text { (BIC) }\end{array}$} & \multirow[t]{2}{*}{$\begin{array}{c}\text { Sample-Size } \\
\text { Adjusted BIC }\end{array}$} & \multicolumn{3}{|c|}{ Chi-Square } & \multirow[t]{2}{*}{ CFI } & \multicolumn{3}{|c|}{ RMSEA } & \multirow[t]{2}{*}{ SRMR } \\
\hline & Ho Value & H1 Value & & & & Estimate & DF & $\mathbf{p}$ & & Estimate & 90 Percent C.I. & $\mathbf{p}$ & \\
\hline M1 & -19791.063 & -18447.216 & 39816.126 & 40296.126 & 39924.816 & 2687.694 & 623 & .000 & 0.657 & 0.086 & 0.0830 .089 & 0.000 & 0.096 \\
\hline M2 & -19780.762 & -18447.216 & 39795.524 & 40275.523 & 39904.213 & 2667.091 & 623 & .000 & 0.660 & 0.086 & 0.0820 .089 & 0.000 & 0.098 \\
\hline M3 & -20119.190 & -18447.216 & 40462.379 & 40921.866 & 40566.424 & 3343.947 & 628 & .000 & 0.548 & 0.098 & 0.0950 .102 & 0.000 & 0.118 \\
\hline M4 & -19566.382 & -18447.216 & 39374.763 & 39871.173 & 39487.169 & 2238.331 & 619 & .000 & 0.731 & 0.077 & $0.073 \quad 0.080$ & 0.000 & 0.082 \\
\hline M5 & -19218.700 & -18447.216 & 38715.401 & 39285.656 & 38844.527 & 1542.968 & 601 & .000 & 0.843 & 0.059 & 0.0560 .063 & 0.000 & 0.069 \\
\hline
\end{tabular}


1

Table 6. Labels, original items by Rybowiak et al. (1999), items' translation in Italian (italics, in brakets) and factor loadings of the 8-factor Confirmatory Factor model.

\begin{tabular}{|c|c|c|}
\hline Label & Item & Loadings \\
\hline \multicolumn{3}{|c|}{ ERROR RISK TAKING } \\
\hline RSK1 & $\begin{array}{l}\text { If one wants to achieve at work, one has to risk making } \\
\text { mistakes. [Se qualcuno vuole riuscire nel lavoro, deve } \\
\text { rischiare di fare qualche errore] }\end{array}$ & .618 \\
\hline RSK2 & $\begin{array}{l}\text { It is better to take the risk of making mistakes than to `sit on } \\
\text { one's behind. [E meglio assumersi il rischio di compiere } \\
\text { qualche errore, piuttosto che stare a guardare] }\end{array}$ & .783 \\
\hline RSK3 & $\begin{array}{l}\text { To get on with my work, I gladly put up with things that can } \\
\text { go wrong. [Per andare avanti con il mio lavoro, accetto di } \\
\text { buon grado che le cose che possano andare male] }\end{array}$ & .687 \\
\hline RSK4 & $\begin{array}{l}\text { I'd prefer to err, than to do nothing at all. [Preferisco } \\
\text { sbagliare piuttosto che non fare nulla] }\end{array}$ & .448 \\
\hline \multicolumn{3}{|c|}{ THINKING ABOUT ERRORS } \\
\hline TNK1 & $\begin{array}{l}\text { After I have made a mistake, I think about how it came about. } \\
\text { [Dopo aver commesso un errore, penso a come sia accaduto] }\end{array}$ & 652 \\
\hline TNK2 & $\begin{array}{l}\text { I often think: 'How could I have prevented this?' [Spesso } \\
\text { penso: Come avrei potuto prevenire questa cosa?] }\end{array}$ & .696 \\
\hline TNK3 & $\begin{array}{l}\text { If something goes wrong at work, I think it over carefully. } \\
\text { [Se qualcosa a lavoro va storta, ci rifletto su attentamente] }\end{array}$ & .617 \\
\hline TNK4 & $\begin{array}{l}\text { After a mistake has happened, I think long and hard about } \\
\text { how to correct it. [Dopo che è successo un errore, penso } \\
\text { molto a lungo a come correggerlo] }\end{array}$ & .731 \\
\hline TNK5 & $\begin{array}{l}\text { When a mistake occurs, I analyze it thoroughly. [Quando mi } \\
\text { capita un errore, lo analizzo a fondo] }\end{array}$ & .657 \\
\hline
\end{tabular}

ERROR COMMUNICATION

COM1 When I make a mistake at work, I tell others about it in order that they do not make the same mistake. [Quando faccio un errore a lavoro, lo dico ai colleghi in modo che non lo ripetano]

COM2 If I cannot rectify an error by myself, I turn to my colleagues. [Se non riesco a porre rimedio a un errore da solo, $\mathrm{mi}$ rivolgo ai colleghi]

COM3 If I cannot manage to correct a mistake, I can rely on others.

[Se non riesco a correggere un errore, posso fare

affidamento sugli altri]

COM4 When I have done something wrong, I ask others, how I should do it better. [Quando ho fatto qualcosa di sbagliato, ho chiesto agli altri come poter migliorare]

\section{ERROR COMPETENCE}

CPT1 When I have made a mistake, I know immediately how to correct it. [Se ho fatto un errore, so immediatamente come correggerlo]

CPT2 When I do something wrong at work, I correct it immediately. [Quando faccio qualcosa di sbagliato a lavoro, lo correggo immediatamente] 
CPT3 If it is at all possible to correct a mistake, then I usually know how to go about it. [Se è possibile correggere un errore, in genere io so come affrontare la cosa]

CPT4 I don't let go of the goal, although I may make mistakes. [Non abbandono il mio obiettivo, anche quando mi capita di fare qualche errore]

\begin{tabular}{cl}
\hline LEARNING FROM ERRORS \\
\hline LRN1 & $\begin{array}{l}\text { Mistakes assist me to improve my work. [Gli errori mi sono } \\
\text { d'aiuto per migliorare il mio lavoro] }\end{array}$ \\
LRN2 & $\begin{array}{l}\text { Mistakes provide useful information for me to carry out my } \\
\text { work. [Gli errori mi forniscono informazioni utili per } \\
\text { svolgere il mio lavoro] }\end{array}$ \\
LRN3 & $\begin{array}{l}\text { My mistakes help me to improve my work. [Gli sbagli mi } \\
\text { aiutano a migliorare il mio lavoro] }\end{array}$ \\
LRN4 & $\begin{array}{l}\text { My mistakes have helped me to improve my work. [Gli } \\
\text { errori che ho compiuto mi hanno aiutato a migliorare il mio } \\
\text { lavoro] }\end{array}$ \\
\hline ERROR ANTICIPATION \\
\hline ANT1 & $\begin{array}{l}\text { In carrying out my task, the likelihood of errors is high. } \\
\text { [Nello svolgere i miei compiti, la probabilità di fare errori è } \\
\text { elevata] }\end{array}$
\end{tabular}

ANT2 Whenever I start some piece of work, I am aware that mistakes occur. [Ogni volta che inizio una nuova attività, sono consapevole che possono verificarsi degli errori]

ANT3 Most of the time I am not astonished about my mistakes because I expected them. [La maggior parte delle volte non mi sorprendo dei miei errori perché me li aspettavo]

ANT4 I anticipate mistakes happening in my work. [Prevedo gli errori che capitano nel mio lavoro]

ANT5 I expect that something will go wrong from time to time. [Mi aspetto che qualcosa possa andare storto di tanto in tanto]

\begin{tabular}{clc}
\hline ERROR STRAIN & .647 \\
STR1 & $\begin{array}{l}\text { I find it stressful when I err. [Mi sento stressato/a quando } \\
\text { sbaglio] }\end{array}$ & .664 \\
STR2 & $\begin{array}{l}\text { I am often afraid of making mistakes. [Sono spesso } \\
\text { preoccupato/a di poter fare errori] }\end{array}$ & .674 \\
STR3 & $\begin{array}{l}\text { I feel embarrassed when I make an error. [Mi sento in } \\
\text { imbarazzo quando mi capita di fare un errore] }\end{array}$ \\
STR4 & $\begin{array}{l}\text { If I make a mistake at work, I 'lose my cool' and become } \\
\text { angry. [Se faccio un errore a lavoro, perdo la calma e mi } \\
\text { arrabbio] }\end{array}$ & .715 \\
STR5 & $\begin{array}{l}\text { While working I am concerned that I could do something } \\
\text { wrong. [Mentre lavoro sono preoccupato/a di poter fare }\end{array}$ & .493 \\
$\quad \begin{array}{l}\text { qualcosa di sbagliato] } \\
\text { COVERING UP wITH ERRORS }\end{array}$ & .631 \\
\hline COV1 & $\begin{array}{l}\text { Why mention a mistake when it isn't obvious? [Perché } \\
\text { parlare di un errore quando non è evidente?] }\end{array}$ \\
COV2 $\begin{array}{l}\text { It is disadvantageous to make one's mistakes public. [Non è } \\
\text { conveniente rendere pubblici gli errori di qualcuno] }\end{array}$ & .580 \\
COV3 $\begin{array}{l}\text { I do not find it useful to discuss my mistakes. [Non trovo } \\
\text { utile discutere dei miei errori] }\end{array}$ & .783
\end{tabular}


RUNNING HEAD: Error orientation at work

COV4 It can be useful to cover up mistakes. [Può essere vantaggioso coprire gli errori]

COV5 I would rather keep my mistakes to myself. [Preferisco tenere per me i miei errori]

COV6 Employees who admit to their errors, make a big mistake. [I dipendenti che ammettono i propri errori fanno un grande sbaglio] 
2 Table 7. Correlations among variables and their internal consistency (Cronbach's alphas in parentheses).

\begin{tabular}{|c|c|c|c|c|c|c|c|c|c|c|c|c|c|c|c|c|}
\hline Error orientation's factors & Mean & $S D$ & Skewness & Kurtosis & RSK & TNK & $\mathrm{COM}$ & $\mathrm{CPT}$ & LRN & ANT & STR & $\mathrm{COV}$ & ERR-S & ERR-M & PWD & UAV \\
\hline 1. RSK-Error risk taking & 3,82 & 0.63 & -.281 & -.327 & $(.716)$ & & & & & & & & & & & \\
\hline 2. TNK-Thinking about errors & 3.55 & 0.77 & -.206 & .086 & $.310^{* *}$ & $(.822)$ & & & & & & & & & & \\
\hline 3. COM-Error communication & 3.82 & 0.56 & -.117 & -.163 & $.262^{* *}$ & $.396^{* *}$ & $(.780)$ & & & & & & & & & \\
\hline 4. CPT-Error competence & 3.80 & 0.79 & -.120 & -.099 & $.327^{* *}$ & $.430^{* *}$ & $.315^{* *}$ & $(.710)$ & & & & & & & & \\
\hline 5. LRN-Learning from errors & 2.81 & 0.57 & -.436 & -.199 & $.545^{* *}$ & $.488^{* *}$ & $.324^{* *}$ & $.331^{* *}$ & $(.875)$ & & & & & & & \\
\hline 6. ANT-Error anticipation & 3.60 & 0.72 & .039 & .655 & $.341^{* *}$ & $.316^{* *}$ & $.168^{* * *}$ & $.157^{* *}$ & $.321^{* *}$ & $(.597)$ & & & & & & \\
\hline 7. STR-Error strain & 2.60 & 0.71 & .238 & .195 & -.060 & $.253^{* *}$ & .012 & $-.167^{* *}$ & .076 & $.424^{* *}$ & $(.781)$ & & & & & \\
\hline 8. $\mathrm{COV}-$ Covering up errors & 1.92 & 0.66 & .587 & .190 & $-.205^{* *}$ & $-.146^{* *}$ & $-.303^{* *}$ & $-.166^{* *}$ & $-.215^{* *}$ & $.196^{* *}$ & $.398^{* *}$ & $(.797)$ & & & & \\
\hline 9. ERR-S-Errors (slips/lapses) & 2.51 & 0.68 & .063 & -.271 & .004 & -.044 & $-.157^{* *}$ & $-.291^{* *}$ & -.011 & $.104^{*}$ & $.247^{* *}$ & $.223^{* *}$ & $(.730)$ & & & \\
\hline 10. ERR-M-Errors (mistakes) & 2.19 & 0.77 & .524 & -.077 & .073 & -.016 & $-.165^{* *}$ & $-.247^{* *}$ & .004 & $.205^{* *}$ & $.199^{* *}$ & $.235^{* *}$ & $.570^{* *}$ & $(.824)$ & & \\
\hline 11. PWD-Power distance & 2.86 & 0.81 & .235 & -.254 & -.013 & .029 & $-.214^{* *}$ & -.032 & -.052 & $.118^{*}$ & $.207^{* *}$ & $.217^{* *}$ & $.231^{* *}$ & $.209^{* *}$ & $(.785)$ & \\
\hline 12. UAV-Uncert. avoidance & 3.87 & 0.68 & -.406 & -.035 & .073 & $.324^{* *}$ & $.243^{* *}$ & $.274^{* *}$ & $.198^{* *}$ & .064 & .064 & $-.132^{* *}$ & -.062 & $-.186^{* *}$ & $.155^{* *}$ & $(.821)$ \\
\hline Factor score determinacy & & & & & .90 & .92 & .90 & .88 & .94 & .86 & .91 & .90 & .90 & .91 & .92 & .91 \\
\hline
\end{tabular}

$\begin{aligned} 4 & \\ 5 & \text { Note: } * * \mathrm{p}<.01 \\ 6 & \\ 7 & \\ 8 & \\ 9 & \\ 10 & \end{aligned}$

